\title{
Molecular mechanisms of Treg-mediated T cell suppression
}

\author{
Angelika Schmidt, Nina Oberle ${ }^{\dagger}$ and Peter H. Krammer ${ }^{*}$ \\ Division of Immunogenetics, Tumorimmunology Program, German Cancer Research Center (DKFZ), Heidelberg, Germany
}

\section{Edited by:}

Kendall A. Smith, Weill Medical

College of Cornell University, USA

Reviewed by:

Christopher E. Rudd, University of Cambridge, UK

Balbino Alarcon, Consejo Superior de Investigaciones Cientificas, Spain

Pushpa Pandiyan, National Institutes of Health, USA

\section{*Correspondence:}

Peter H. Krammer, Division of

Immunogenetics, Tumorimmunology

Program, German Cancer Research

Center, Im Neuenheimer Feld 280,

D-69120 Heidelberg, Germany.

e-mail:p.krammer@

$d k f z$-heidelberg.de

${ }^{+}$Nina Oberle and Peter H. Krammer have contributed equally to this work.
$\mathrm{CD}^{+}{ }^{+} \mathrm{CD} 25^{\text {high }} \mathrm{Foxp}^{+}$regulatoryT cells (Tregs) can suppress other immune cells and, thus, are critical mediators of peripheral self-tolerance. On the one hand, Tregs avert autoimmune disease and allergies. On the other hand, Tregs can prevent immune reactions against tumors and pathogens. Despite the importance of Tregs, the molecular mechanisms of suppression remain incompletely understood and controversial. Proliferation and cytokine production of $\mathrm{CD} 4{ }^{+} \mathrm{CD} 25^{-}$conventionalT cells (Tcons) can be inhibited directly by Tregs. In addition, Tregs can indirectly suppress Tcon activation via inhibition of the stimulatory capacity of antigen presenting cells. Direct suppression of Tcons by Tregs can involve immunosuppressive soluble factors or cell contact. Different mechanisms of suppression have been described, so far with no consensus on one universal mechanism. Controversies might be explained by the fact that different mechanisms may operate depending on the site of the immune reaction, on the type and activation state of the suppressed target cell as well as on the Treg activation status. Further, inhibition of T cell effector function can occur independently of suppression of proliferation. In this review, we summarize the described molecular mechanisms of suppression with a particular focus on suppression of Tcons and rapid suppression of T cell receptor-induced calcium $\left(\mathrm{Ca}^{2+}\right)$, NFAT, and NF-kB signaling in Tcons by Tregs.

Keywords: Treg, TCR signaling, suppression mechanisms

\section{INTRODUCTION: DISCOVERY AND PROPERTIES OF REGULATORY T CELLS}

Regulatory T cells (Tregs) play an indispensable role in the immune system as they are involved in the prevention of autoimmune diseases, allergies, infection-induced organ pathology, transplant rejection as well as graft versus host disease (GvHD) by suppression of effector $\mathrm{T}$ cells and other immune cells (Sakaguchi, 2004). However, Tregs can also dampen immune responses against tumors, as described for various types of cancer (Zou, 2006; Curiel, 2008). Conversely, in certain situations, Tregs can also protect against cancer by controlling cancer-associated inflammation (Gounaris et al., 2009). Therefore, Tregs are subject to intense investigations.

The history of Tregs begins in 1970 (Gershon and Kondo, 1970). Unfortunately, due to lack of a molecular marker, research on suppressor $\mathrm{T}$ cells was stopped, until many years later Sakaguchi et al. (1995) identified CD25 as a phenotypic marker for suppressive $\mathrm{CD}^{+}{ }^{+} \mathrm{T}$ cells in mice. These suppressive $\mathrm{T}$ cells were named Tregs and were later also found in humans within the $\mathrm{CD} 4{ }^{+} \mathrm{CD} 25^{\text {high }} \mathrm{T}$ cell population (Baecher-Allan et al., 2001; Dieckmann et al., 2001; Jonuleit et al., 2001; Levings et al., 2001; Stephens et al., 2001; Taams et al., 2001). Constitutive expression of CD25 is restricted to Tregs in naïve mice while in humans, only cells that highly express CD25 designate Tregs, and activated $\mathrm{T}$ cells acquire intermediate levels of CD25 (Sakaguchi et al., 1995; Baecher-Allan et al., 2001). Importantly, Foxp3 was identified as a lineage-defining transcription factor for Tregs in mice (Fontenot et al., 2003; Hori et al., 2003; Khattri et al., 2003) and humans (Yagi et al., 2004; Roncador et al., 2005). In mice, up to $90 \%$ of Tregs express Foxp3, while resting as well as activated conventional T cells do not show detectable levels of Foxp3. Analogous to mice, the majority of human $\mathrm{CD} 4{ }^{+} \mathrm{CD} 25^{\text {high }}$ Tregs also express Foxp3. However, in contrast to mice, human conventional $\mathrm{T}$ cells (Tcons) transiently express intermediate levels of Foxp3 upon activation (Pillai et al., 2007), questioning Foxp3 as a specific marker for human Tregs. While the necessity of Foxp3 for suppressive function of Tregs is undisputed, contradictory reports leave it unclear whether (temporary) Foxp3 expression is sufficient to confer suppressive abilities to human activated $\mathrm{T}$ cells. Some studies demonstrated suppressive capacities of Foxp $3^{+}$activated human T cells (Walker et al., 2003; Pillai et al., 2007) while others did not (Gavin et al., 2006; Wang et al., 2007; Allan et al., 2007). However, activation-induced transient Foxp3 induction in human Tcons was not observed in other studies (Yagi et al., 2004). These discrepancies might be due to differences in culture conditions, such as strength of T cell receptor (TCR) stimulation and presence of IL-2 or TGF- $\beta$. For example, Shevach's group found that TCR-induced Foxp3 expression in human naïve Tcons is indeed dependent on TGF- $\beta$, but does not result in a suppressive phenotype (Tran et al., 2007). In addition, his group claimed that a certain antibody clone used for staining of human Foxp3 results in unspecific staining of activated T cells, although this is controversial (Pillai and Karandikar, 2008). Conflicting results may also be ascribed to differences in kinetics and level of Foxp3 expression and, consequently, expression of Foxp3 target genes (Allan et al., 2008; Zheng et al., 2008).

Foxp $3^{+}$Tregs are not a uniform population but rather comprise several subphenotypes. The majority of human Tregs displays 
a CCR7 ${ }^{-} \mathrm{CD}^{-} 5 \mathrm{RA}^{-}$effector/memory phenotype (Beyer and Schultze, 2007). However, only the naïve CD45RA ${ }^{+}$Treg subset maintains Treg phenotype and function upon ex vivo expansion (Hoffmann et al., 2006). A detailed characterization of the human Foxp $3^{+}$Treg repertoire suggested a further grouping into CD 45RA ${ }^{+}$Foxp $3^{\text {low }}$ resting Tregs, CD45RA ${ }^{-}$Foxp $3^{\text {high }}$ activated Tregs, and CD45RA ${ }^{-}$Foxp $3^{\text {low }}$ cytokine-secreting Tregs, the latter being non-suppressive (Miyara et al., 2009). Further, several subphenotypes of murine Tregs with distinct transcriptional signatures were found in different anatomical locations (Feuerer et al., 2009, 2010). Diverse Treg subpopulations may apply different suppression mechanisms and specifically control certain effector cell types. In this review, we mainly focus on naturally occurring Tregs (nTregs), which are thymus-derived. Yet peripheral tolerance is not only ensured by nTregs but also involves various induced Treg populations (iTregs), which seem to play a role mainly in the intestine (Curotto de Lafaille and Lafaille, 2009).

\section{MOLECULAR MECHANISMS OF Treg-MEDIATED SUPPRESSION}

Tregs can suppress a variety of immune cells including B cells, NK cells, NKT cells, CD4 ${ }^{+}$, and $\mathrm{CD}^{+}{ }^{+} \mathrm{T}$ cells, as well as monocytes and dendritic cells (DCs). In the following, we will focus on suppression of $\mathrm{CD} 4{ }^{+} \mathrm{CD} 25^{-}$conventional T cells (Tcons).

Upon cell-cell contact, Tregs inhibit TCR-induced proliferation and IL-2 transcription of Tcons, as shown for murine Tregs already in 1998 (Thornton and Shevach, 1998). Suppression of murine (Ermann et al., 2001) or human (Dieckmann et al., 2001) Tcon proliferation by Tregs can occur directly, i.e., in the absence of antigen presenting cells (APCs). This direct suppression can involve immunosuppressive cytokines or other factors; however, contact-dependent direct suppression has also been described. In addition, Tregs can inhibit Tcons indirectly by influencing the activation status of APCs and therefore activation of Tcons. Based on these properties, a standard assay to assess Treg function is inhibition of responder Tcon proliferation upon stimulation via the TCR in the presence of APCs. A main function of Tregs is suppression of activation and expansion of naïve Tcons, but they can also inhibit activated effector $\mathrm{T}$ cells and memory $\mathrm{CD}^{+}(\mathrm{Lev}-$ ings et al., 2001) and $\mathrm{CD}^{+}$(Suvas et al., 2003) T cells. To be suppressive, Tregs themselves have to be TCR-activated in the presence of IL-2 (Takahashi et al., 1998; Thornton and Shevach, 1998; de la Rosa et al., 2004; Thornton et al., 2004a,b) while costimulation via CD28 is dispensable (Takahashi et al., 2000). However, a more recent study questioned the requirement for Treg activation: Szymczak-Workman et al. (2009) showed that TCR-transgenic Tregs were able to suppress Tcons with different antigen specificity in the absence of the Treg-cognate antigen. Differences in the type of APCs used in the assays, the transgenic system, or "pre-activation" by the cell purification procedure might provide an explanation for the controversy. Yet, the study is in line with other reports that show that Tregs, once active, can suppress Tcons independently of antigen, leading to so-called bystander suppression (Thornton and Shevach, 2000; Karim et al., 2005).

Different mechanisms of Treg-mediated suppression have been described, mostly on the basis of in vitro suppression assays. These mechanisms may also operate in vivo depending on the target cell type and activation status as well as the location and cytokine and microorganism milieu of the immune reaction. Thus, the contribution of suppressive mechanisms might be interpreted differently depending on the cell types and their activation state used in in vitro suppression assays. In addition, differences may occur depending on the readout, as suppressing the production of certain effector cytokines or the release of cytotoxic granules in vivo and in vitro can occur without concomitant suppression of proliferation (Mempel et al., 2006; Schmidt et al., 2011; Sojka and Fowell, 2011). For example, using another in vivo model, it was shown that Tcon expansion in response to antigen was suppressed by Tregs relatively late, yet the remaining Tcons still cycled and produced effector cytokines at these late time points (Klein et al., 2003). It was suggested that activation and/or expansion of antigen-specific Tregs may be a prerequisite for suppression of Tcons in vivo, as it might result in sufficient Treg numbers to enable contact with target Tcons at the site of the immune response (Klein et al., 2003).

The described mechanisms of Treg-mediated T cell suppression are summarized in Figure $\mathbf{1}$ and will be described in more detail in the following sections.

\section{MODULATION OF APC FUNCTION BY Tregs THROUGH CTLA-4 AND OTHER MOLECULES}

The coinhibitory molecule CTLA-4 is constitutively expressed in murine and human Tregs and exposed on the cell surface upon activation (Read et al., 2000; Takahashi et al., 2000; Dieckmann et al., 2001). A role for CTLA-4 in suppression in vivo has been suggested, since CTLA-4 deficiency or blockade in mice results in spontaneous autoimmunity, which can be ameliorated by Tregs (Bachmann et al., 1999; Takahashi et al., 2000). In addition, CTLA4 blockade abrogates the protective effects of Tregs in murine colitis models (Read et al., 2000). Also in vitro suppression of murine Tcon proliferation (in the presence of APCs) was shown to be abrogated in some studies by CTLA-4 blockage (Takahashi et al., 2000; Tang et al., 2004). However, CTLA-4 deficient Tregs could still suppress through compensatory mechanisms involving TGF- $\beta$ and IL-10 in vitro and in vivo (Tang et al., 2004; Read et al., 2006). Similarly, studies with human Tregs do not show a uniform picture: some in vitro studies did not find an involvement of CTLA-4 in Treg-mediated suppression of Tcon proliferation (Baecher-Allan et al., 2001; Levings et al., 2001), while others could partially abrogate suppression by CTLA- 4 blockage (Birebent et al., 2004). These discrepancies may be explained by the involvement of CTLA-4 in some but not all aspects of suppression. Our results showed that rapid Treg-mediated suppression of cytokine transcription in human Tcons was unaffected by CTLA-4 blockage, irrespective of the presence or absence of APCs, while suppression of proliferation in the presence of APCs was partially dependent on CTLA-4 (Schmidt et al., 2011).

Regarding CTLA-4 blockade in long-term experiments, it has to be considered that CTLA-4 is also expressed by activated Tcons after 1-2 days of TCR stimulation (Walunas et al., 1994) and thus cell-intrinsic negative signals are involved. These include competition with the costimulatory molecule CD28 for binding to the B7 molecules CD80 (B7.1) and CD86 (B7.2; van der Merwe et al., 


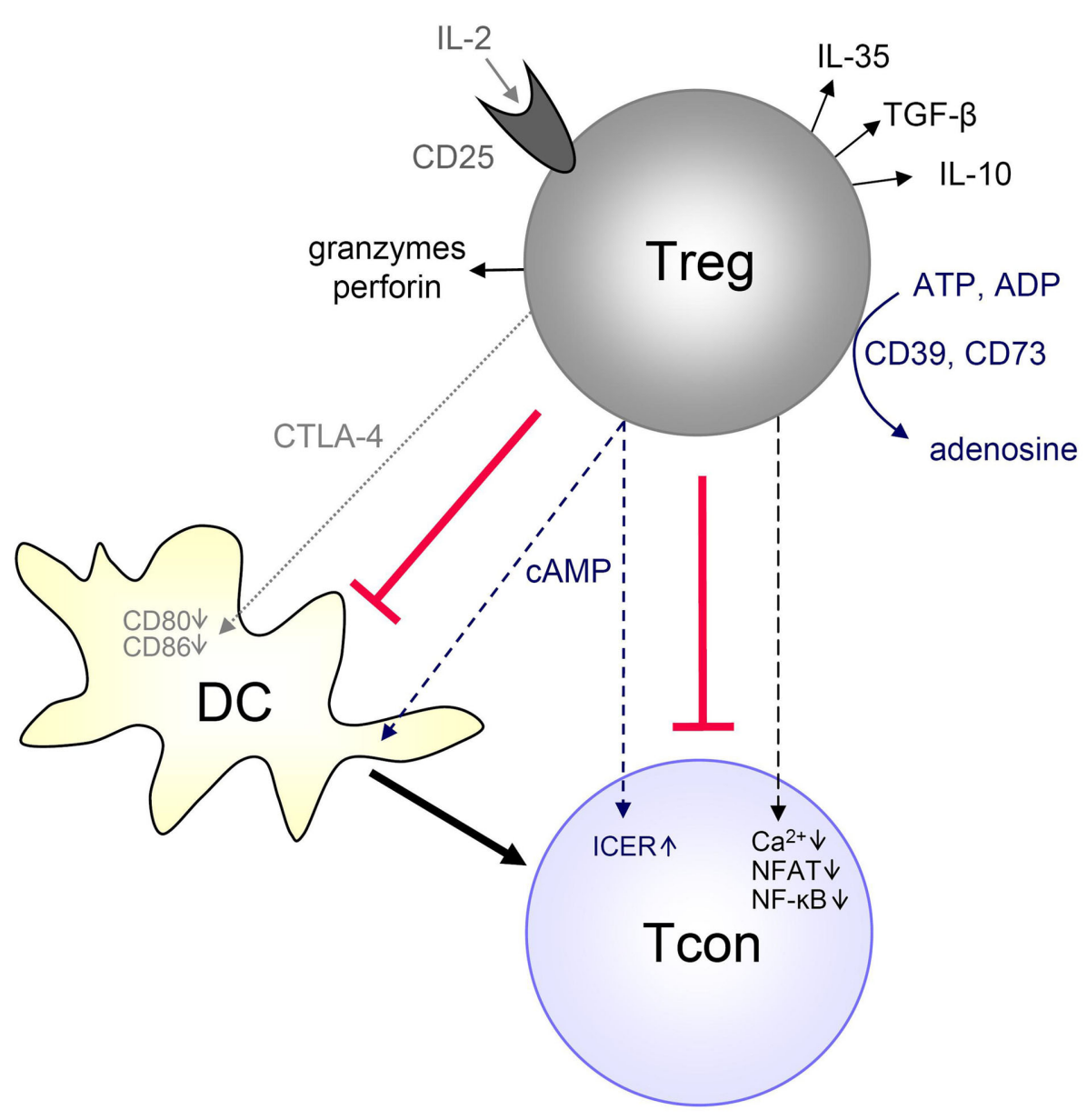

FIGURE 1 | Mechanisms of Treg-mediated Tcon suppression. Tregs have been described to suppress Tcons by different mechanisms, depending on the experimental setup, site and type of immune response. Tregs can generate immunosuppressive adenosine or transfer cAMP to Tcons. Tregs can rapidly suppress TCR-induced $\mathrm{Ca}^{2+}$, NFAT, and NF-kB signaling. Tregs can also produce immunosuppressive cytokines (IL-10, TGF- $\beta$, IL-35), and they can suppress by IL-2 consumption or induce effector cell death via granzyme and perforin. Furthermore, Tregs can suppress Tcons indirectly by downregulating costimulatory molecules on APCs (such as DCs) via CTLA-4. Details are described in the text.
1997), transduction of negative signals that induce cell cycle arrest and prevent IL-2 secretion (Krummel and Allison, 1996; Walunas et al., 1996), and limiting T cell contact with APCs (Schneider et al., 2006). Recently, the molecular mechanism of Treg-mediated suppression via CTLA-4 was elucidated in more detail. Downregulation of CD80/CD86 expression on APCs by Tregs (Cederbom et al., 2000) was shown to be partly dependent on CTLA-4 and the adhesion molecule LFA-1, thereby indirectly inhibiting Tcon activation by APCs in vitro (Oderup et al., 2006; Onishi et al., 2008) and in vivo (Wing et al., 2008). Mechanistically, downregulation of CD80/CD86 on target cells by CTLA-4-expressing cells can involve capture of these ligands by CTLA-4, a process called trans-endocytosis (Qureshi et al., 2011). Another study supports the importance of CTLA-4 in in vivo suppression without direct effects on the responder T cells (Friedline et al., 2009). Strikingly, mice with Treg-specific ablation of CTLA-4 spontaneously develop fatal autoimmune disease (Wing et al., 2008), underlining the importance of CTLA-4 expression on Tregs for the maintenance of peripheral tolerance.
In contrast to the studies showing necessity of CTLA-4 for Tregmediated suppression, Tran et al. (2009) applied a mixed coculture system with murine and human cells and showed that human Tregs can suppress proliferation of murine Tcons by targeting murine DCs through LFA-1:ICAM-1 interaction between Tregs and DCs. Suppression was only evident in the presence of APCs, and it was not abrogated when human CTLA- 4 was blocked. Interestingly, murine Tregs could not suppress human Tcons in the presence of human APCs. These results argue for species-specific differences in suppressive molecules, especially regarding CTLA- 4 .

Certain human and murine DC subsets express the enzyme indoleamine 2,3-dioxygenase (IDO) that catalyzes degradation of tryptophan to kynurenine, leading to starvation of effector $\mathrm{T}$ cells and also to direct cell cycle arrest. At the same time, IDO leads to iTreg generation (Fallarino et al., 2003, 2006; Curti et al., 2007). Tregs themselves can, via CTLA-4-induced signaling, further increase IDO expression in DCs. Additionally it was shown that murine Tregs diminish glutathione synthesis in DCs, presumably CTLA-4-mediated, which leads to a redox environment 
unfavorable for Tcon proliferation (Yan et al., 2009, 2010). In conclusion, the importance of CTLA-4 in Treg-mediated suppression is undisputed, but it does not seem to be the only suppressive mechanism, and also species differences may exist. Importantly, CTLA-4 blockage has already shown promising outcomes in clinical trials for metastatic melanoma, presumably due to its effects on both effector T cells and Tregs (Peggs et al., 2009). Despite the prominent role for CTLA-4 in Treg-mediated inhibition of DC activation, involvement of the costimulatory molecule CD40, the deubiquitinase A20 acting as antigen-presentation attenuator, and the surface receptor neuropilin-1 has also been described (Hanig and Lutz, 2008; Sarris et al., 2008; Song et al., 2008). Further, the adhesion molecule LAG-3 is expressed on Tregs, binds to MHC class II molecules and was proposed to be involved in suppression, since deficiency or blockage of LAG-3 resulted in disturbance of $\mathrm{T}$ cell homeostasis in vivo and reduced suppressive activity of Tregs in vitro (Huang et al., 2004; Workman and Vignali, 2005). These effects might be mediated by LAG-3-induced inhibition of DC activation (Liang et al., 2008). However, LAG-3 deficient mice do not show signs of autoimmune disease. Further, MHC class II expression on an activated human Treg subpopulation that exerts rapid contact-dependent suppression seems to be important (Baecher-Allan et al., 2006) as blockage of MHC class II on activated Tregs was shown to abrogate suppression (Peiser et al., 2007).

Tregs do not only reduce antigen presenting activity of APCs but also support an immunosuppressive cytokine milieu by reducing IL- 6 while increasing IL-10 production by DCs (Veldhoen et al., 2006). In addition to these mechanisms, Tregs can inhibit Tcon activation by reduction of contact formation between Tcons and DCs (Tadokoro et al., 2006). As already mentioned, there is mutual interplay between Tregs and tolerogenic DCs, the latter acting in induction and expansion of Tregs.

\section{SUPPRESSION VIA THE IMMUNOSUPPRESSIVE CYTOKINES TGF- $\beta$, IL-10, AND IL-35}

The role of immunosuppressive cytokines in Treg-mediated suppression is still incompletely understood. Despite the importance of TGF- $\beta$ and IL-10 in several in vivo models, these cytokines seem to be dispensable for other disease models such as autoimmune gastritis (Suri-Payer and Fritzsching, 2006) as well as for most in vitro systems. Treg-mediated suppression via cytokines is described in more detail below.

\section{TGF- $\beta$}

TGF- $\beta 1$ deficient mice develop T cell-mediated autoimmunity within several weeks after birth (Li et al., 2006b). A similar phenotype is observed in mice lacking TGF- $\beta$ responsiveness specifically in T cells ( $\mathrm{Li}$ et al., 2006a; Marie et al., 2006). Tregs can produce high amounts of membrane-bound and soluble TGF- $\beta$, and blocking TGF- $\beta$ partially abrogated suppression of T cell proliferation in vitro using murine or human T cells (Nakamura et al., 2001, 2004; Levings et al., 2002), suggesting that Treg-produced TGF$\beta$ controls autoimmunity. However, other groups did not find involvement of TGF- $\beta$ in Treg-mediated suppression of T cells (Baecher-Allan et al., 2002; Piccirillo et al., 2002; Godfrey et al., 2005; Oberle et al., 2007). Although TGF- $\beta$ deficient Tregs could suppress Tcon proliferation in vitro, TGF- $\beta 1$ production by Tregs was necessary to prevent colitis in several studies (Read et al., 2000; Izcue et al., 2009). In addition, TGF- $\beta$ RII knockout Tcons could not be suppressed in vivo in colitis models, but TGF- $\beta$ produced by other cells than Tregs was likely involved in these models (Mamura et al., 2004; Fahlen et al., 2005). Along that line, TGF- $\beta$ produced by DCs in the gut was critical to prevent colitis by Treg induction (Travis et al., 2007). Nevertheless, mice with T cell-specific TGF- $\beta 1$ deficiency showed enhanced Th1 and Th 2 responses and immunopathology including colitis, underscoring the importance of T cell-produced TGF- $\beta$; however, these mice were resistant to the induction of experimental autoimmune encephalitis (EAE) likely due to impaired Th17 induction (Li et al., 2007). Therefore, the role of TGF- $\beta$ in Treg-mediated suppression might depend very much on the type of effector cell and the site of the immune response, and TGF- $\beta$ may even promote proinflammatory Th 17 responses. Interestingly, human Tregs could confer suppressive activity to target Tcons in a cell-contact-dependent manner (so-called infectious tolerance). Suppressive cells generated by infectious tolerance use a mechanism involving TGF- $\beta$ (Jonuleit et al., 2002). A more recent study shows that infectious tolerance in mice requires membranebound TGF- $\beta$ on Tregs (Andersson et al., 2008). Thus, TGF- $\beta$ function in vivo probably does not only involve direct suppression of effector $\mathrm{T}$ cell signaling but also induction of Tregs, consistent with lethal autoimmune disease and reduced peripheral Treg numbers in TGF- $\beta 1$ deficient mice (Marie et al., 2005).

\section{IL-10}

The cytokine IL-10 exerts mainly immunosuppressive effects on various cell types (Moore et al., 2001). IL-10 plays an important role in Treg-mediated suppression of intestinal inflammation, since blocking IL-10 or using IL-10 deficient Tregs abrogates the protective effect of Tregs on $\mathrm{T}$ cell transfer-induced colitis (Asseman et al., 1999). Importantly, while the control of memory/antigen-experienced $\mathrm{T}$ cells during prevention or cure of colitis required IL-10, Treg-dependent prevention of naïve $\mathrm{T}$ cell-mediated colitis does not require IL-10 (Asseman et al., 2003; Uhlig et al., 2006), highlighting the involvement of different suppression mechanisms depending on the activation status of the target cell. The importance of IL-10 in Treg function in vivo has been extended to infection and EAE models (McGeachy and Anderton, 2005; Belkaid, 2007). Further, another study showed that Treg-derived IL-10 is important for control of inflammation at environmental interfaces but seems to be dispensable for control of systemic autoimmunity (Rubtsov et al., 2008). Along that line, IL-10 or IL-10 receptor deficient mice do not develop autoimmunity, but are susceptible to colitis in the presence of triggering flora (Kuhn et al., 1993; Spencer et al., 1998). Importantly, the IL-10 locus was identified as a susceptibility locus in ulcerative colitis (Franke et al., 2008), a form of human inflammatory bowel disease (IBD). Furthermore, IL-10RA or IL-10RB mutations result in severe early onset IBD (Glocker et al., 2009). Although IL-10 can suppress various immune cells including DCs, direct effects of IL-10 on effector/memory T cells are important in prevention of T cell-mediated colitis (Kamanaka et al., 2011). Two recent studies further delineate that IL-10R signaling is needed in Tregs as well as in Th17 cells in order to suppress colonic Th17 
responses (Chaudhry et al., 2011; Huber et al., 2011). Adding to the complexity of IL-10 function in Treg-mediated suppression, it was recently shown that Tregs need IL-10 (and not IL-35 and TGF- $\beta$ ) to control IFN- $\gamma$ production by T cells in the inflamed skin, while IL-10 was dispensable for regulation of IFN- $\gamma$ and T cell expansion in the lymph node (Sojka and Fowell, 2011).

Of note, anti-inflammatory IL-10 might not be produced only by $\mathrm{T}$ cells including Tregs and Foxp $3^{-} \mathrm{T}$ regulatory $1(\mathrm{Tr} 1)$ cells (Roncarolo et al., 2006), but also by other cells such as regulatory B cells (Mauri and Ehrenstein, 2008) and macrophages. The latter were shown to indirectly influence suppression by acting on Tregs to maintain Foxp3 (Murai et al., 2009).

\section{IL-35}

IL-35 is a recently discovered cytokine implicated in Treg-mediated suppression and was shown to directly inhibit Tcon proliferation (Collison et al., 2007). Tregs deficient in one of the IL-35 chains had reduced suppressive ability in vitro and in vivo in an IBD model, although these mice did not show autoimmune disease. In contrast to murine Tregs, human Tregs do not constitutively express IL-35 (Bardel et al., 2008). Nevertheless, IL-35 may play a role also in human immunosuppression, as treatment of naïve human or mouse $\mathrm{T}$ cells with IL-35 induced a so-called $\mathrm{iT}_{\mathrm{R}} 35$ regulatory population that mediated suppression via IL35 but did not require IL-10, TGF- $\beta$, or Foxp3 (Collison et al., 2010). These $\mathrm{iT}_{\mathrm{R}} 35$ were strongly suppressive in several in vivo mouse models. Although naïve human Tregs did not express high amounts of IL-35, long-term activation of human Tregs led to upregulation of the IL-35 subunits starting at 3 days of activation (Chaturvedi et al., 2011). These long-term activated Tregs exerted contact-independent in vitro suppression in an IL-35-dependent manner and also induced $\mathrm{iT}_{\mathrm{R}} 35$ cells. Thus, IL-35 may contribute to infectious tolerance.

\section{SUPPRESSION OF EFFECTOR CELLS BY IL-2 CONSUMPTION AND APOPTOSIS INDUCTION}

One efficient way to repress immune responses would be killing of effector cells by Tregs, which was indeed observed in certain settings. It was shown that upon CD3/CD46 activation, human nTregs express the serine protease granzyme (Gzm) A and kill $\mathrm{CD}^{+} \mathrm{T}$ cells and other target cells in a perforin-dependent manner, yet independent of the death receptor CD95 (Grossman et al., 2004). In another report, contact-dependent suppression of Tcon proliferation by activated murine Tregs in vitro was described to be partially GzmB-dependent; however, in contrast to the results of Grossman et al. perforin was not involved here (Gondek et al., 2005). As suggested from mouse studies, GzmB-mediated suppression might be important in vivo to maintain transplant tolerance (Gondek et al., 2008), but it might counteract tumor clearance by killing tumor-reactive NK cells and CD8 ${ }^{+}$T cells (Cao et al., 2007). Involvement of the death receptor TRAIL in Treg-mediated suppression of activated mouse Tcons was shown in vitro and in vivo in a transplantation model, but required strong pre-activation of Tcons and Tregs (Ren et al., 2007).

The importance of IL-2 consumption by Tregs due to their high CD25 expression remains controversial. A study by Lenardo's group proposed that Tregs induce IL-2 deprivation-mediated apoptosis in mouse Tcons, which was dependent on close proximity between the cells (Pandiyan et al., 2007). However, the authors did not observe suppression of IL-2 production during the first $48 \mathrm{~h}$ of coculture, which is not in line with many other studies (Thornton and Shevach, 1998; Barthlott et al., 2005; Sojka et al., 2005). Pandiyan et al. (2007) found that T cells deficient in the proapoptotic protein Bim could not be suppressed in vitro and in vivo in a T cell transfer-induced IBD model. In contrast to these results, a recent study by Vignali's group did not find involvement of cell death induction by Tregs (Szymczak-Workman et al., 2011). Szymczak-Workman et al. used responder Tcons that are resistant to cytokine withdrawal-induced apoptosis due to Bim deficiency or Bim/Puma double knockout or Bcl-2 overexpression and performed in vitro and in vivo assays to conclude that Tregs do not suppress via induction of apoptosis in responder Tcons. In addition to these mouse studies, we (Oberle et al., 2007) and others (Vercoulen et al., 2009) also did not observe apoptosis induction in human Tcons by human Tregs.

IL-2 does not only promote survival but also proliferation of $\mathrm{T}$ cells, and IL-2 consumption seems to be involved in reducing the positive effects of IL-2 on proliferation and IL-2 expression, because exogenous IL-2 could abrogate Treg-mediated suppression of proliferation and/or of IL-2 production in vitro (Thornton and Shevach, 1998; Baecher-Allan et al., 2001; de la Rosa et al., 2004). However, during inhibition of murine Tcons by human Tregs, IL-2 consumption was not causative for suppression of proliferation, as blocking human CD25 did not abrogate suppression under optimal stimulation conditions for the human Tregs (Tran et al., 2009). Of note, under suboptimal stimulation conditions, human Tregs required CD25 signals in order to be functionally suppressive, yet the suppression mechanism under these conditions remains elusive and may or may not involve IL-2 consumption (Tran et al., 2009). We found that, although exogenous IL-2 partially abrogated suppression of human Tcon proliferation by human Tregs, rapid suppression of IL-2 transcription by human pre-activated Tregs was not affected (Oberle et al., 2007), which argues for different suppression mechanisms for proliferation and cytokine transcription. Here, IL-2 itself led to increased IL-2 mRNA expression (Oberle et al., 2007), however, for later time points, negative feedback of IL-2 on IL-2 mRNA and protein expression was described (Villarino et al., 2007). These differences in the effect of IL-2 on IL-2 expression may depend on time point, species, amount of IL-2 and cellular activation status and may contribute to the inconsistent results on the role of IL2 consumption in Treg-mediated suppression. Together, the role of IL-2 consumption remains controversial and may depend on the specific setting and stimulation conditions of the Tregs. IL-2 consumption by Tregs may even enhance certain effector $\mathrm{T}$ cell reactions, which was shown for Th17 responses (Pandiyan et al., 2011). In addition, the link of IL-2 consumption to apoptosis is unclear, as exogenous IL-2 could rescue proliferation of suppressed human Tcons without reducing background apoptosis (Vercoulen et al., 2009).

Together, it can be concluded from these studies that IL-2 consumption by Tregs and apoptosis induction in suppressed target cells may only play a role in suppression under certain circumstances. 


\section{SUPPRESSION VIA EXPRESSION OF EFFECTOR T CELL-SPECIFIC TRANSCRIPTION FACTORS}

Tregs may be specialized to suppress a certain $\mathrm{CD} 4^{+} \mathrm{T}$ cell subset in particular by expression of the hallmark transcription factor of this very subset. In this regard, it was shown that a Treg subset upregulated T-bet in response to IFN- $\gamma$, which was essential for the control of Th1-mediated inflammation (Koch et al., 2009). Similarly, IRF-4 (which is typically made by Th2 and Th17 cells) expression in Tregs was required for suppression of Th2 responses (Zheng et al., 2009). Moreover, expression of STAT3 (which drives Th17 differentiation) in Tregs was increased and crucial during control of Th17-mediated intestinal pathology (Chaudhry et al., 2009). Adding to that list, loss of the Th2-associated transcription factor GATA-3 in Tregs led to autoimmune disease, in that case accompanied by destabilization of Foxp3 expression and elevated Th1, Th2, and Th17 cytokine levels (Wang et al., 2011). GATA-3 deficient Tregs tended to convert into a Th17 phenotype, and it was further shown that GATA-3 was upregulated upon stimulation in murine as well as human Tregs (Wohlfert et al., 2011). However, the mechanism through which Tregs suppress via expression of effector $\mathrm{T}$ cell-specific transcription factors is currently unclear but might involve competition for limiting factors. The transcription factors could directly interact with Foxp3, as described for IRF-4, STAT3, and ROR $\gamma \mathrm{t}$. Expression of the effector $\mathrm{T}$ cell-specific transcription factors and their regulated genes such as chemokine receptors might also enable Tregs to migrate to and proliferate at the site of immune response. Accordingly, suppressor activity of IRF-4 or STAT3 knockout Tregs in vitro was shown to be unimpaired, and GATA-3 was selectively expressed by Tregs at environmental interfaces.

In contrast, expression or activation of Th-specific transcription factors in Tregs might lead to a loss of Foxp3 expression and suppressive function. For example, STAT3 was described to mediate downregulation of Foxp3, and intriguingly, STAT3 is activated by several cytokines which negatively regulate Tregs and Foxp3, such as IL-6, IL-23, or IL-27 (Yang et al., 2007, 2008; Yao et al., 2007; Huber et al., 2008; Ahern et al., 2010). Thus, loss of STAT3 expression in $\mathrm{T}$ cells during $\mathrm{T}$ cell transfer-induced colitis and systemic inflammation increased Treg induction and ameliorated disease (Durant et al., 2010).

Plasticity between $\mathrm{CD} 4^{+} \mathrm{T}$ cell subsets might be higher than originally anticipated, although the stability of the Treg lineage in vivo is highly controversial (Zhou et al., 2009; Rubtsov et al., 2010). Yet several lines of evidence indicate that plasticity is particularly pronounced between Th17 cells and iTregs (Lee et al., 2009), and an intermediate state with expression of both ROR $\gamma \mathrm{t}$ and Foxp3 at the same time was observed (Lochner et al., 2008; Zhou et al., 2008). In certain cytokine milieus, even induction of IL-17 was described in murine and human Tregs, which might retain suppressive function (Xu et al., 2007; Koenen et al., 2008; Osorio et al., 2008; Beriou et al., 2009; Voo et al., 2009).

\section{ADENOSINE AS IMMUNOSUPPRESSIVE MOLECULE}

Hydrolysis of extracellular ATP to ADP or AMP by the ectoenzyme CD39, expressed by all murine Tregs and by about $50 \%$ of human Tregs, represents another Treg-mediated anti-inflammatory mechanism (Borsellino et al., 2007). CD39 knockout Tregs showed reduced suppressive capacities in vitro and in vivo (Deaglio et al., 2007). In human Tregs, CD39 expression was suggested to identify a highly suppressive Treg subset (Mandapathil et al., 2009), and suppression of Tcon proliferation by this subset could be partially abrogated by blockage of ectonucleotidase activity (Mandapathil et al., 2010). CD73, also expressed by Tregs, further degrades AMP to adenosine (Kobie et al., 2006). Adenosine signals via the A2A adenosine receptor and may inhibit DCs as well as activated T cells, e.g., by elevation of cyclic AMP (cAMP; Ernst et al., 2010). In human but not mouse T cells, ATP can also directly increase cAMP levels through the $\mathrm{P}_{2} \mathrm{Y}_{11}$ receptor (Abbracchio et al., 2006). In vivo, A2A receptor signaling might induce anergy and promote iTreg generation (Zarek et al., 2008). In conclusion, generation of adenosine seems to be important for the suppressive function of certain Treg subsets.

\section{SUPPRESSION VIA CAMP, ICER, AND NFAT}

Tregs produce high levels of cAMP and cAMP amounts were shown to rise in suppressed Tcons upon contact with Tregs, presumably via transfer through gap junctions from murine Tregs to Tcons (Bopp et al., 2007). Accumulation of high cAMP amounts in Tregs might require Treg pre-activation (Bazhin et al., 2010). cAMP seems to be an important component of Treg-mediated suppression, since suppression of IL-2 transcription and proliferation could be partly abrogated by a cAMP antagonist or a gap junction inhibitor (Bopp et al., 2007). The same group recently also showed that induction of cAMP in murine DCs upon Treg coculture contributes to suppression of DCs (Fassbender et al., 2010). The authors suggest that in suppressed Tcons, cAMP acts by inducing expression of the inducible cAMP early repressor (ICER), which functions as a repressor, e.g., at the IL-2 and IL-4 gene loci (Bodor et al., 2000). ICER protein and mRNA were previously shown to be increased in suppressed mouse T cells after 17-20 h of Tcon:Treg coculture stimulation (Bodor et al., 2007a) which correlated with an increase in cAMP (Bopp et al., 2007). In these studies, an increase in ICER and cAMP was not yet detectable after $4-5 \mathrm{~h}$. In human Tcons, we also did not observe ICER upregulation upon coculture with Tregs compared to coculture with Tcons within $5 \mathrm{~h}$ (Oberle et al., 2007; Oberle and Schmidt, unpublished data). Since NFAT1/4 double knockout Tcons cannot be fully suppressed by Tregs in long-term suppression assays, such as proliferation or IL-2 mRNA and protein expression after $18 \mathrm{~h}$ (Bopp et al., 2005), it was proposed that NFAT forms inhibitory complexes on cytokine promoters with transcriptional repressors such as ICER, PPR $\gamma$, or p21 ${ }^{\text {SNFT }}$ (Bandyopadhyay et al., 2007; Bodor et al., 2007a,b). However, by calculating the percentage of suppression, partial inhibition can be observed although NFAT1/4 double knockout T cells display hyperproduction of IL-2, suggesting that NFAT1/4 double knockout Tcons are less susceptible, but not completely resistant to Treg-mediated suppression. Furthermore, although ICER failed to accumulate in suppression assays with $\mathrm{B} 7$ deficient responder $\mathrm{T}$ cells (as ICER induction in suppressed T cells was CTLA-4/B7 and GITR-dependent), residual suppression was still detectable (Bodor et al., 2007a). These results argue for additional suppressive mechanisms together with those mediated by CTLA- 4 and ICER:NFAT. More recently, it was proposed that NFAT2 together with ICER translocates to the nucleus 
to confer repression of the IL-2 promoter in murine T cells upon coculture with Tregs (Vaeth et al., 2011). However, depending on the experimental setting, either increased or decreased NFAT2 nuclear translocation was observed in suppressed compared to control mouse $\mathrm{T}$ cells, while ICER clearly translocated into the nucleus upon Treg-mediated suppression (Vaeth et al., 2011).

Together with a report showing that Cbl-b deficient $\mathrm{T}$ cells are less sensitive to suppression by Tregs (Wohlfert et al., 2004), data on inhibitory NFAT complexes imply that Treg-suppressed Tcons display features of anergy, as both NFAT1 and Cbl-b are crucial in anergy induction (Macian et al., 2002; Soto-Nieves et al., 2009). Anergy induction in suppressed Tcons might occur later than inhibition of cytokine transcription since we did not detect accumulation of ICER mRNA or other anergy-related genes up to $5 \mathrm{~h}$ after TCR stimulation in suppressed compared to control human Tcons (Oberle et al., 2007). By comparing gene expression of suppressed and anergized murine Tcons, Sukiennicki and Fowell (2006) found only partial overlap of NFAT-dependent gene expression while most genes did not overlap. However in their study, changes in gene expression were not yet pronounced $12 \mathrm{~h}$ after coculture, but only evident after $36 \mathrm{~h}$. This is in contrast to the gene array performed with human $\mathrm{T}$ cells in our group, in which, e.g., NFAT and NF-кB target genes were already suppressed in human Tcons within 1.5-3 h of coculture; however, this gene array was performed with pre-activated Tregs (Schmidt et al., 2011). Thus, discrepancies may be due to Treg pre-activation or species.

In contrast to its role in anergy induction, NFAT also plays an important activating role in TCR-induced transcription of T cell effector cytokines. This rapid TCR-induced NFAT activation in Tcons is suppressed by Tregs, which will be described in the next section.

\section{RAPID SUPPRESSION OF TCR-INDUCED CALCIUM, NFAT AND NF-KB SIGNALING AND CONSEQUENTLY CYTOKINE TRANSCRIPTION IN Tcons UPON SUPPRESSION BY TregS}

Signaling events and in particular TCR signaling in responder Tcons upon suppression by Tregs has not been studied extensively so far. Yet detailed knowledge might be important for therapeutic interventions in certain $\mathrm{T}$ cell-mediated diseases, as resistance of effector $\mathrm{T}$ cells to Treg-mediated suppression frequently occurs in autoimmune diseases (Buckner, 2010). However, kinetics of cytokine suppression has been analyzed in detail. Our group previously showed that inhibition of cytokine transcription occurs rapidly within 1-3 h (Oberle et al., 2007). This suppression of cytokine transcription was also observed when stronger TCR/CD28 stimulation was applied and occurred within 3045 min when pre-activated Tregs were used (Schmidt et al., 2011). Thornton and Shevach (1998) showed potent inhibition of IL-2 mRNA production in murine Tcons by Tregs, though the authors did not analyze earlier than $15 \mathrm{~h}$. Further experiments with murine Tcon:Treg cocultures showed that IL-2 mRNA suppression starts between 5 and $6 \mathrm{~h}$ of coculture stimulation (Barthlott et al., 2005) or even later, after 6-12 h (Sojka et al., 2005). In a subsequent paper, the latter group did not observe IL-2 mRNA suppression after $12 \mathrm{~h}$ of coculture (Sukiennicki and Fowell, 2006). In contrast to our experiments, these studies were conducted in the presence of APCs and with murine T cells. Thus, discrepancies in IL-2 mRNA suppression kinetics might be due to species differences or experimental setup regarding strength of stimulation and presence of APCs. There may also be differences in responder Tcon susceptibility to suppression, which could be influenced by the cell purification procedure and resting time between purification and initiation of cocultures. In addition, we used pre-activated Tregs, while the others did not. Nevertheless, when Sojka et al. used pre-activated Tregs, they still observed suppression of IL-2 secretors not earlier than $4-6 \mathrm{~h}$ after initiation of coculture. However, at earlier points in time, the induction of IL-2 also was still very low (Sojka et al., 2005).

To analyze Treg-mediated effects on Tcons, we favored an in vitro cell culture system without APCs. Thus, we could analyze direct effects of Tregs on Tcons and we obtained pure populations of responder Tcons after coculture. However, it is still a matter of debate whether the main targets of Treg-mediated suppression in vivo are $\mathrm{T}$ cells or rather APCs. It remains possible that Tregs utilize distinct mechanisms to directly suppress Tcons or APCs, and both mechanisms might play a role in vivo. Although several studies have shown that murine as well as human Tregs inhibit TCR-induced proliferation of Tcons in the absence of APCs (Dieckmann et al., 2001; Ermann et al., 2001), others found that murine Tregs fail to inhibit Tcons stimulated by anti-CD3 antibodies (Thornton and Shevach, 2000). In general, significant suppression in the absence of APCs is mostly observed at high (1:1) Treg to Tcon ratios, which makes cell density very important to control. Nevertheless, as APC-containing cocultures may represent a more physiological setting than Tcon:Treg cocultures without APCs, we also used another in vitro cell culture system to show that rapid suppression of cytokine transcription can occur in the presence of APCs (Schmidt et al., 2011).

Transcription of several effector $\mathrm{T}$ cell cytokines is initiated upon TCR stimulation and costimulation by the cognate antigenic peptide presented on a mature APC or, artificially, by agonistic anti-CD3 and anti-CD28 antibodies. As we observed rapid suppression of cytokine transcription, we questioned whether Tregs directly influence TCR signaling. Until recently, there was no comprehensive study on TCR signaling events in Tcons upon suppression by Tregs. TCR stimulation leads to a cascade of protein phosphorylation and dephosphorylation events, which ultimately activates transcription factors to initiate a distinct transcriptional program (Lin and Weiss, 2001; Smith-Garvin et al., 2009). The most important transcription factors for the induction of cytokine expression are NF-кB, NFAT, and AP-1, which together mediate activation of several cytokine genes, e.g., IL-2 and IFN- $\gamma$ (Jain et al., 1995; Young, 1996; Sica et al., 1997). Before we describe our results regarding TCR signaling in Treg-suppressed Tcons, we will give a brief introduction into TCR signaling.

\section{OVERVIEW: TCR SIGNALING}

Activation of the NF- $\kappa$ B, NFAT, and AP-1 signaling pathways starts with TCR stimulation-induced phosphorylation of TCRassociated CD3 chains by the Src family kinases Fyn and Lck, leading to binding of ZAP-70. ZAP-70 phosphorylates the adapter protein LAT, which is critical for recruitment of important signaling proteins, leading to activation of Phospholipase C $\gamma 1$ (PLC $\gamma 1$; 
Qi and August, 2007). Active PLC $\gamma 1$ cleaves phosphatidylinositol 4,5-bisphosphate $\left(\mathrm{PIP}_{2}\right)$ to generate the second messengers diacylglycerol (DAG) and inositol 1,4,5-trisphosphate $\left(\mathrm{IP}_{3}\right)$. DAG mediates its effects via membrane recruitment and, thus, activation of signaling proteins, whereas $\mathrm{IP}_{3}$ induces calcium $\left(\mathrm{Ca}^{2+}\right)$ influx into the cytosol. Activation of both NF- $\kappa B$ and NFAT requires the activity of $\mathrm{PLC} \gamma 1$, while the AP- 1 pathway is largely PLC $\gamma 1$-independent. These signaling pathways are summarized in Figure 2 and will be described in more detail, although still simplified, below.

\section{Ca ${ }^{2+}$ signaling}

The main pathway to initiate a $\mathrm{Ca}^{2+}$ signal in T cells is via $\mathrm{IP}_{3}$ binding to $\mathrm{IP}_{3}$ receptors $\left(\mathrm{IP}_{3} \mathrm{Rs}\right)$ in the endoplasmatic reticulum (ER) membrane, which leads to release of $\mathrm{Ca}^{2+}$ from the ER into the cytoplasm. Depletion of the ER $\mathrm{Ca}^{2+}$ store induces $\mathrm{Ca}^{2+}$ influx from outside the cell by a process called store-operated calcium entry (SOCE). The stromal interaction molecule (STIM) senses ER $\mathrm{Ca}^{2+}$ store depletion and in turn triggers opening of calcium release-activated calcium (CRAC) channels in the plasma membrane, leading to $\mathrm{Ca}^{2+}$ entry from the extracellular space into the cytoplasm (Quintana et al., 2005; Feske, 2007).

T cells express three types of $\mathrm{IP}_{3}$ Rs to varying degrees depending on their stage of differentiation (Grafton and Thwaite, 2001). It is not clear which $\mathrm{IP}_{3} \mathrm{R}$ is the most important receptor in peripheral $\mathrm{T}$ cells, and knowledge of regulation of these receptors by molecules other than $\mathrm{IP}_{3}$ is very limited. $\mathrm{IP}_{3}$-mediated $\mathrm{Ca}^{2+}$ store depletion appears to be the main mode of $\mathrm{Ca}^{2+}$ entry in lymphocytes (Oh-Hora and Rao, 2008). However, $\mathrm{Ca}^{2+}$ release from intracellular stores can be initiated not only by $\mathrm{IP}_{3}$, but cyclic $\mathrm{ADP}$ ribose (cADPR) seems to be important for long-lasting release of $\mathrm{Ca}^{2+}$ from stores (Guse et al., 1999; Schwarzmann et al., 2002). Further, nicotinic acid adenine dinucleotide phosphate (NAADP) was described to act prior to $\mathrm{IP}_{3}$ and cADPR to provide sufficient $\mathrm{Ca}^{2+}$ amounts to sensitize $\mathrm{IP}_{3} \mathrm{Rs}$ (Gasser et al., 2006). Regarding plasma membrane $\mathrm{Ca}^{2+}$ channels, there is evidence that CRAC channels are most critical for TCR signal transduction (Feske et al., 2005), but the L-type voltage-gated $\mathrm{Ca}^{2+}$ channel Cav1.4 also seems to be important for TCR signaling and T cell homeostasis (Omilusik et al., 2011). STIM1 seems to be the predominant player

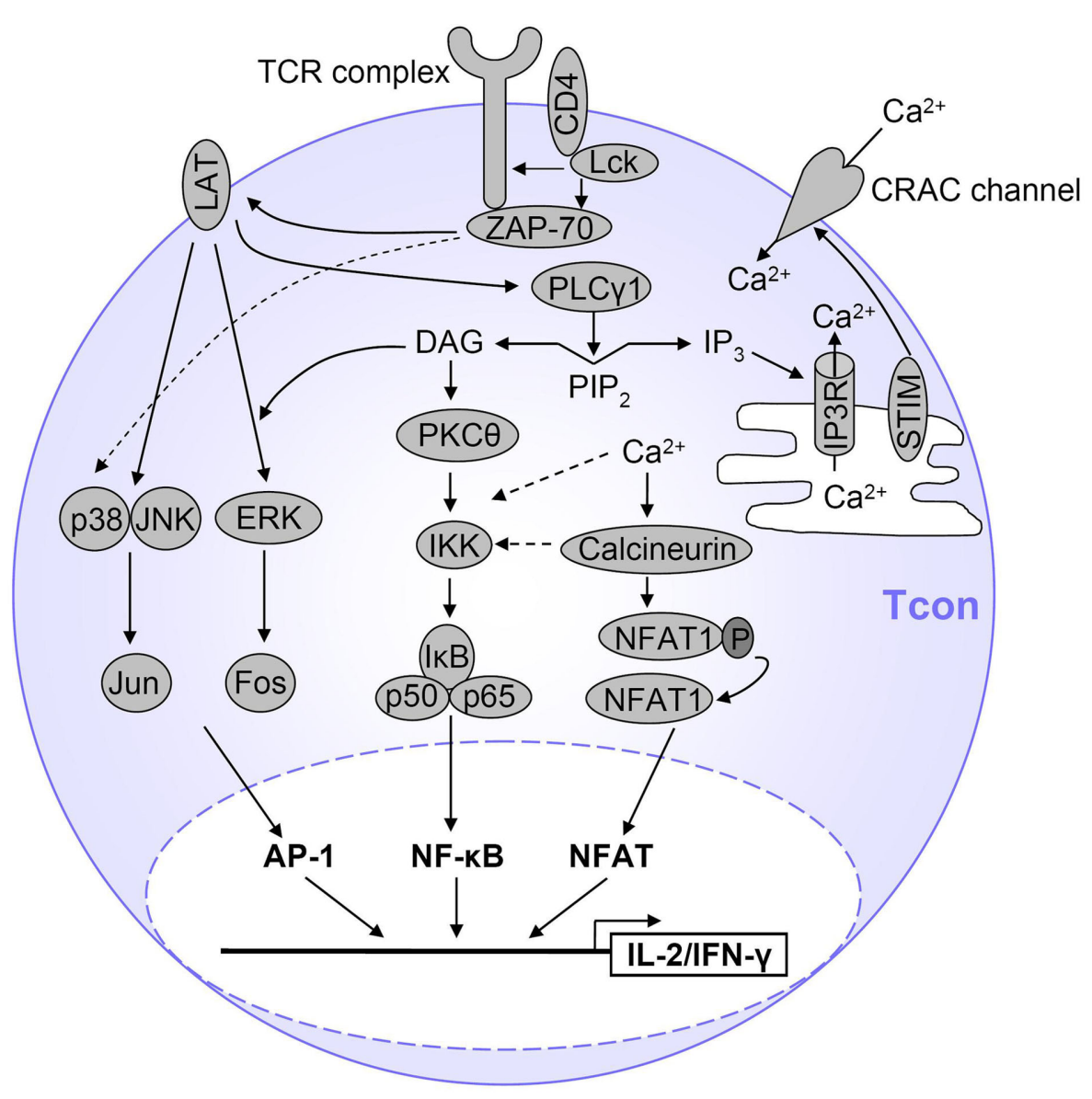

FIGURE 2 | Simplified view of TCR signaling in T cells. After TCR stimulation, several pathways are initiated which ultimately result in $\mathrm{T}$ cell activation, proliferation and expression of cytokines such as IL-2 and IFN- $\gamma$. The main transcription factors involved are AP-1, NFAT, and NF-KB. AP-1 is activated by a MAPK cascade. NF-KB is activated by PKC $\theta$-dependent activation of the IKK complex and subsequent $I_{\kappa} \mathrm{B}$ degradation, and $\mathrm{Ca}^{2+}$ also contributes to NF-KB activation. NFAT is activated by $\mathrm{Ca}^{2+}$ influx which activates the NFAT-dephosphorylating phosphatase calcineurin. Only the major pathways are displayed here and represent a simplified view of TCR signaling. Details are described in the text. 
of SOCE in T cells although both STIM1 and STIM2 can reconstitute SOCE in STIM1 deficient T cells (Oh-Hora et al., 2008). However, STIM1 as well as STIM2 knockout T cells show severely impaired $\mathrm{Ca}^{2+}$ entry, impaired NFAT activation and cytokine production. Of note, these cells can still proliferate in vivo (Oh-Hora et al., 2008). Interestingly STIM1, which is very abundant in lymphocytes but not in excitable cells, inhibits voltage-gated $\mathrm{Ca}_{\mathrm{V}} 1.2$ channels while it activates the CRAC constituent ORAI (Park et al., 2010; Wang et al., 2010).

\section{NFAT activation}

NFAT activation in $\mathrm{T}$ cells is dependent on the generation of a $\mathrm{Ca}^{2+}$ signal, which activates the $\mathrm{Ca}^{2+}$ :calmodulin-dependent phosphatase calcineurin. Calcineurin dephosphorylates NFAT, thus unmasking its nuclear localization sequence and enabling transport of NFAT into the nucleus. The NFAT family consists of five members, three of which are expressed by T cells: NFAT1 (also called NFATp or NFATc2), NFAT2 (NFATc or NFATc1), and NFAT4 (NFATx or NFATc3; Macian, 2005), and each of them appears in several isoforms. The constitutively expressed NFAT1 represents the main NFAT isoform in resting T cells (Macian et al., 2002). Although NFAT can act as a transcription factor alone or in homodimers, many transcription factors interact with NFAT to activate or inhibit transcription, amongst them AP-1. Various cytokine promoters, e.g., IL-2, IL-4, IL-5, IFN- $\gamma$, and TNF- $\alpha$ contain cooperative NFAT:AP-1 binding sites which greatly enhance transcription of the respective cytokine (Rao et al., 1997; Chinenov and Kerppola, 2001; Macian et al., 2001; Hermann-Kleiter and Baier, 2010). Of note, AP-1 binding to the IL-2 promoter becomes undetectable in the absence of NFAT (Jain et al., 1993). Interestingly, it could be shown that differences in $\mathrm{Ca}^{2+}$ influx change the number of IL-2 expressing human $\mathrm{CD} 4^{+} \mathrm{T}$ cells rather than the amount of IL-2 expression per cell, suggesting an all-or-nothing response in $\mathrm{Ca}^{2+}$-induced IL-2 (and IFN- $\gamma$ ) production. NFAT was identified as the molecular switch being either in or outside the nucleus, while nuclear translocation of NF- $\mathrm{B}$ and expression of exclusive NF- $\kappa$ B target genes was graded (Podtschaske et al., 2007).

\section{$N F$ - $\mathrm{B}$ activation}

In resting $\mathrm{T}$ cells, the NF- $\kappa \mathrm{B}$ heterodimer is associated with the cytosolic inhibitor of $\kappa \mathrm{B}(\mathrm{I} \kappa \mathrm{B})$, which masks its nuclear localization sequence (Vallabhapurapu and Karin, 2009). Several NF-кB and I $\mathrm{B}$ family members exist, from which the p65:p50:I $\mathrm{B} \alpha$ complex is the most prominent NF- $\kappa \mathrm{B}: \mathrm{I} \kappa \mathrm{B}$ complex in T cells. After TCR triggering, DAG is important for localization and, thus, activation of PKC $\theta$ (Isakov and Altman, 2002). PKC $\theta$ activates the NF- $\kappa$ B pathway by modulation of the CARMA1:Bcl-10:MALT1 (CBM) complex, which then activates the trimeric IKK complex comprising the catalytic subunits IKK $\alpha$ and IKK $\beta$ as well as the regulatory subunit IKK $\gamma$. The catalytic subunits of the active IKK complex phosphorylate I $\kappa \mathrm{B} \alpha$, leading to I $\mathrm{B} \alpha$ polyubiquitination and subsequently its proteasomal degradation, allowing for translocation of NF- $\kappa \mathrm{B}$ to the nucleus. Importantly, NF- $\kappa \mathrm{B}$ activation is also influenced by $\mathrm{Ca}^{2+}$ (see below).

The NF- $\kappa \mathrm{B}$ complex itself can be phosphorylated and acetylated, which regulates its transcriptional activity and association with other transcription factors (Li and Verma, 2002; Perkins,
2006). For example, phosphorylation of p65 on serine (Ser)529 and Ser536 in its transactivation domain by IKK $\beta$ may enhance activity (Sakurai et al., 1999).

\section{The AP-1 pathway}

The AP-1 pathway is initiated by a MAPK cascade leading to activation of MAPKs, such as ERK, JNK, and p38 (Dong et al., 2002). LAT recruits certain proteins, which are important for MAPK activation via Ras and Rac. Recent data led to the assumption that in T cells, p38 is not only activated by the classical MAPK cascade but also, and primarily, via an alternative pathway characterized by direct phosphorylation of p38 by ZAP-70 and subsequent p38 autophosphorylation (Mittelstadt et al., 2009). MAPKs promote expression, phosphorylation, and activation of Fos and Jun, which together comprise the AP-1 transcription factor (Johnson and Lapadat, 2002). In contrast to NF- $\mathrm{B}$ and NFAT, the AP-1 pathway is largely independent of PLC $\gamma$, but DAG can enhance Ras recruitment and activation and, thus, ERK1/2 signaling. In addition, calcineurin can contribute to JNK activation (Werlen et al., 1998), however, JNK1/2 seem to be dispensable for primary activation and IL-2 production of T cells (Sabapathy et al., 2001).

\section{TCR SIGNALING IN Tcons UPON Treg-MEDIATED SUPPRESSION}

Previously, our group showed that rapid suppression of Th1 cytokine transcription in human Tcons by Tregs occurs immediately after induction of mRNA transcription (Oberle et al., 2007). The suppression mechanism was independent of TGF- $\beta$ and IL10, IL-2 consumption, initiation of apoptosis, and induction of anergy-related genes in suppressed Tcons. As Tcon inhibition was detected very rapidly, we asked whether Tregs may directly disrupt key components of TCR signaling which could impede Tcon cytokine transcription and, consequently, Tcon function. Indeed, our recent data show that pre-activated human Tregs rapidly suppressed TCR-induced signaling events in Tcons (Schmidt et al., 2011). In detail, TCR-induced $\mathrm{Ca}^{2+}$ release from intracellular stores and, consequently, $\mathrm{Ca}^{2+}$ influx was blocked immediately after TCR stimulation in suppressed Tcons. Inhibition of $\mathrm{Ca}^{2+}$ signals resulted in decreased NFAT1 dephosphorylation and NFAT target gene expression. Also NF- $\kappa \mathrm{B}$ activation, as detected by phosphorylation of IKK, I $\mathrm{B} \alpha$, and $\mathrm{p} 65$ as well as target gene expression, was strongly and rapidly inhibited. $\mathrm{Ca}^{2+}$ suppression appears to be causative for suppression of NFAT, NF- $\kappa$ B, and IL-2, as suppression of either one could be abrogated by artificial $\mathrm{Ca}^{2+}$ store depletion. In contrast, $\mathrm{Ca}^{2+}$-independent events such as TCR-proximal signaling and the AP-1 pathway were not affected in suppressed Tcons. Interestingly, PLC $\gamma 1$ phosphorylation as well as $\mathrm{IP}_{3}$ generation were not altered in suppressed Tcons. Therefore, Tregs inhibit $\mathrm{Ca}^{2+}$ store depletion in Tcons via so far unknown mechanisms.

A summary of these results is shown in Figure 3 and discussed in more detail below.

\section{TCR-proximal and AP-1 signaling}

To our knowledge, there are no studies regarding phosphorylation of TCR signaling molecules in $\mathrm{CD}^{+}$Tcons upon suppression by Tregs. An approach using human $\mathrm{CD} 8^{+} \mathrm{T}$ cells demonstrated that $\mathrm{CD} 3 \zeta$ and ZAP-70 phosphorylation was unaffected by Tregs, though activation of ERK was inhibited (Baatar et al., 2009). In 


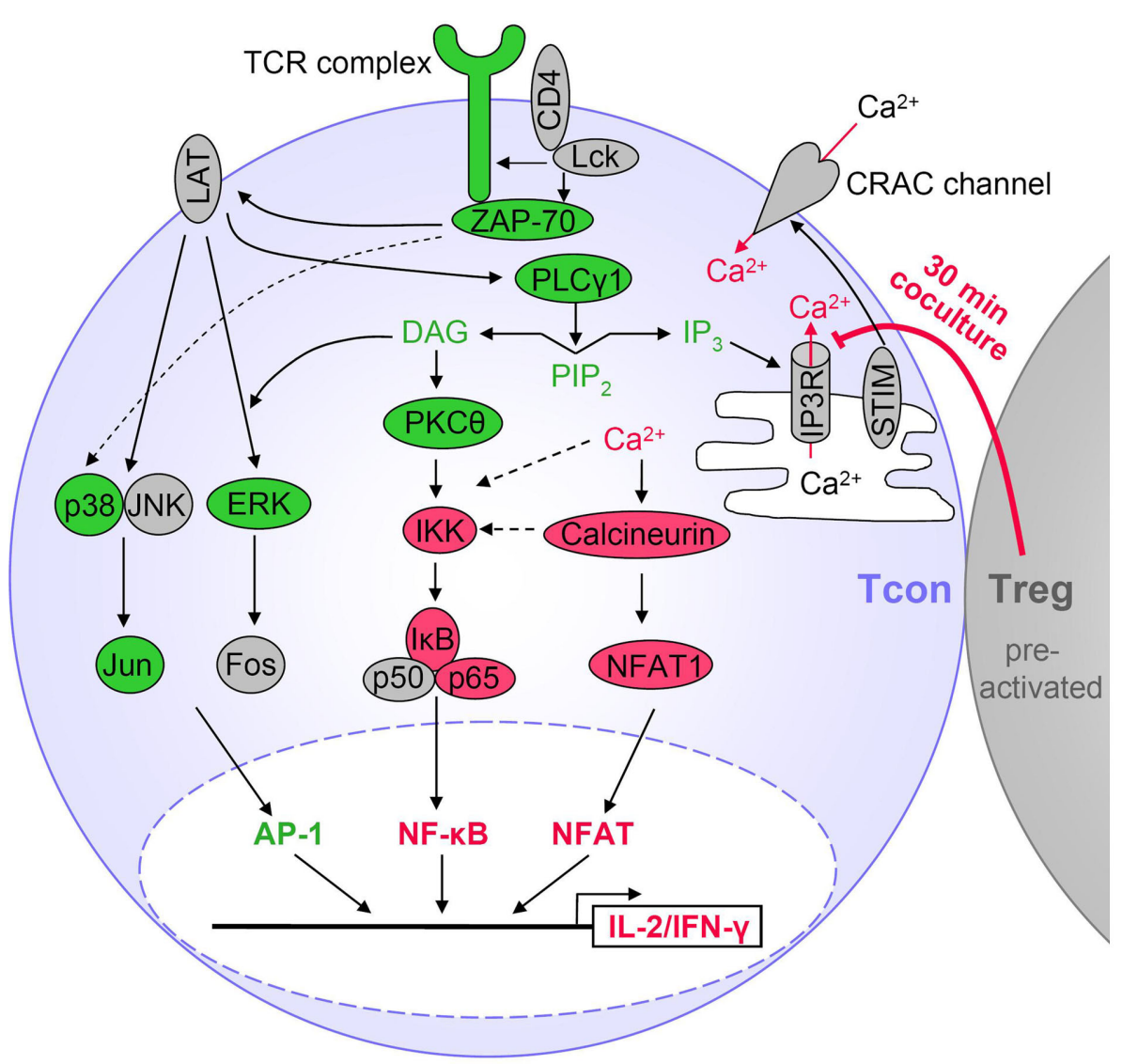

FIGURE 3 | Tregs suppress particularTCR signaling pathways in Tcons. Activated Tregs rapidly suppress cytokine expression in Tcons via inhibition of $\mathrm{Ca}^{2+}$ signals and consequently reduced NF-kB and NFAT activation. Suppression by Tregs requires at least $30 \mathrm{~min}$ of coculture, is favored by cell contact and sustained after Treg removal.
Red indicates Treg-mediated suppression of TCR-induced activation in Tcons. Molecules displayed in green were not inhibited during Treg-mediated rapid suppression of cytokine transcription. Molecules in gray were not analyzed or TCR-induced activation was not detectable. contrast, during rapid suppression of $\mathrm{CD} 4^{+}$Tcons, we did not find inhibition of the AP-1 pathway. This discrepancy might be due to differences between $\mathrm{CD}^{+}$and $\mathrm{CD}^{+} \mathrm{T}$ cells or to the coculture setup as Baatar et al. used non-pre-activated Tregs and cocultures were set up $6 \mathrm{~h}$ before stimulation.

\section{Suppression of calcium signaling in Tcons}

At first glance, our results seem to be in contrast with two other studies which claim that Tregs do not inhibit initial TCR signaling in target $\mathrm{T}$ cells. However, the experimental setup differs. Tang and Krummel (2006) analyzed TCR-induced $\mathrm{Ca}^{2+}$ signals in suppressed murine $\mathrm{T}$ cells in contact with freshly isolated Tregs by microscopic $\mathrm{Ca}^{2+}$ measurements. The authors used a TCRtransgenic system and stimulated with peptide-pulsed B cells. They did not observe suppression of $\mathrm{Ca}^{2+}$ signals in Tcons and concluded that Tregs do not influence TCR-proximal and $\mathrm{Ca}^{2+}$ signaling. However, using non-pre-activated Tregs, $\mathrm{Ca}^{2+}$ suppression may not be detectable as Tregs might not be sufficiently activated within the short time period of these experiments to obtain suppressive capacities (unpublished observation). In addition, species differences might account for the discrepancy between these results and ours. Another study found that sustained $\mathrm{Ca}^{2+}$ increase in human $\mathrm{T}$ helper cells was not affected by Tregs when they were stimulated with superantigen-pulsed B cells (Esquerre et al., 2008). A main difference between these experiments and ours is that the authors explored the effect of expanded Tregs on the effector phase of the immune response and, thus, as target cells they used pre-activated T helper cells which were expanded at least 14 days in vitro. These cells might be less susceptible to Treg-mediated $\mathrm{Ca}^{2+}$ suppression and/or more reactive to stimulation than resting $\mathrm{CD} 4{ }^{+} \mathrm{CD} 25^{-}$Tcons as used in our study. In addition, stimulation by superantigen-pulsed $\mathrm{B}$ cells might be stronger than the anti-CD3/anti-CD28 antibody stimulation used by us. As the authors do not provide data on the initial stimulation-induced increase in $\mathrm{Ca}^{2+}$ concentrations in $\mathrm{T}$ helper cells but focus on the sustained $\mathrm{Ca}^{2+}$ signal, it cannot be discussed whether Tregs would influence the initial increase in $\mathrm{Ca}^{2+}$ immediately after being stimulated by the APC, as we observe for Tcons stimulated with crosslinked anti-CD3/anti-CD28 antibodies. Of note, we also detected rapid suppression of NF- $\kappa \mathrm{B}$ signaling and IL-2 transcription when we used APCs plus anti-CD3 antibodies for stimulation, although we did not perform $\mathrm{Ca}^{2+}$ analyses 
in this setting. Interestingly, Esquerre et al. found that human Tregs (which were in vitro expanded for at least 14 days) inhibited polarization of T helper cell IFN- $\gamma$ toward the APC in a TGF- $\beta$ dependent manner, while inhibition of proliferation and IFN- $\gamma$ production was not affected by TGF- $\beta$ blocking. Together, these data again emphazise that Tregs seem to employ different mechanisms of suppression, depending on the activation state of the Tregs themselves as well as of the responder T cells and suggest differences in inhibition of priming versus inhibition of effector function.

We found that Tregs inhibited $\mathrm{Ca}^{2+}$ signaling without involvement of TCR-proximal signaling molecules, including PLC $\gamma 1$. Similarly, a report by Gri et al. (2008) shows Treg-mediated suppression of $\mathrm{Ca}^{2+}$ signals in murine mast cells in a PLC $\gamma 2$ independent fashion. However, suppression of $\mathrm{Ca}^{2+}$ signals in mast cells did not affect $\mathrm{Ca}^{2+}$ store depletion but rather involved a cAMP-dependent suppression of $\mathrm{Ca}^{2+}$ influx through the plasma membrane. The authors proposed that cAMP alters the membrane potential through unknown mechanisms and decreases permeability of $\mathrm{Ca}^{2+}$ channels, as demonstrated for mast cells previously. This suppression was dependent on interaction of OX40 on Tregs with OX40L on mast cells. In our setup, OX40 is likely not involved since OX40L is not expressed by $\mathrm{T}$ cells, but mainly by APCs. Though suppression of $\mathrm{Ca}^{2+}$ signals might be a general mechanism of Treg action, we describe a cAMP-independent rapid suppression of $\mathrm{Ca}^{2+}$ store depletion in human $\mathrm{T}$ cells. This $\mathrm{Ca}^{2+}$ suppression resulted in immediate inhibition of NF- $\kappa$ B and NFAT activation and, consequently, IL-2 transcription. However, we still observed a late effect with a cAMP antagonist on IL-2 mRNA suppression upon stimulation for approximately $5 \mathrm{~h}$ (unpublished observation), which is in line with results by others using murine Tcons (Bopp et al., 2007). Interestingly, we found that IFN- $\gamma$ suppression was not affected by the cAMP antagonist (unpublished observation). In general, suppression mechanisms might be diverse regarding different cytokines, e.g., by the influence of promoter-specific repressors such as ICER.

The exact mechanism through which Tregs inhibit $\mathrm{Ca}^{2+}$ store depletion in Tcons remains elusive. Since $\mathrm{IP}_{3}$ amounts were unaltered, $\mathrm{IP}_{3}$ metabolism seems unchanged. Treg pre-activation was required to observe this rapid suppression, yet it is unknown which molecular changes take place in Tregs during pre-activation. Furthermore, the receptor for Tregs on Tcons remains elusive; however, our results indicate that triggering of this unknown receptor must lead to a suppressive signal within approximately $30 \mathrm{~min}$. It is tempting to speculate that this rapid process involves signaling via phosphatases or kinases in Tcons. Suppression might involve yet unknown modifications of the $\mathrm{IP}_{3} \mathrm{R}$ which hinder its interaction with $\mathrm{IP}_{3}$. Future studies will be needed to address these questions and decipher the mechanism how Tregs inhibit $\mathrm{Ca}^{2+}$ signals in Tcons. In addition, it would be interesting to analyze potential differences in $\mathrm{Ca}^{2+}$ suppression when distinct Treg subsets are used. Further, there may be differences in suppression of diverse target T cell types. Although Tregs can suppress Th1, Th2, and Th17 cytokines, one could speculate that $\mathrm{Ca}^{2+}$ suppression may be irrelevant for Th17 suppression, since $\mathrm{IP}_{3} \mathrm{R}$-mediated $\mathrm{Ca}^{2+}$ release is needed for initial IL- 2 and IFN- $\gamma$ production, but negatively regulates IL-17 production (Nagaleekar et al., 2008). Of note, several studies found that Th17 cells tend to be refractory to Tregmediated suppression (Stummvoll et al., 2008; Chauhan et al., 2009; Vercoulen et al., 2009), although the underlying mechanism remains to be investigated.

\section{NFAT1 suppression}

In addition to the rapid suppression of NFAT1 dephosphorylation we described, it is possible that after several hours of Treg:Tcon interaction, NFAT also exerts a repressive role by forming inhibitory complexes with other transcription factors on cytokine promoters, as described for NFAT:ICER complexes. Different roles of NFAT depending on the experimental readout are also implied by data from Vaeth et al. (2011) who observed increased NFAT2 nuclear translocation upon contact to Tregs in an adoptive $\mathrm{T}$ cell transfer model while in an in vitro coculture assay of murine Tcons and Tregs in the presence of APCs, they show decreased NFAT2 nuclear translocation. The latter result corresponds to our data for human NFAT1. Vaeth et al. analyzed NFAT2/ICER translocation not earlier than $24 \mathrm{~h}$ after stimulation. We could not detect NFAT2 in primary human Tcons upon shortterm stimulation (unpublished observation), in line with reports describing that NFAT2/ $\alpha$ A, the most prominent NFAT2 isoform in peripheral T cells, is only weakly expressed in the naïve state and induced following CD3/CD28 stimulation (Serfling et al., 2006). In conclusion, NFAT2:ICER complexes may play a role in suppression of pre-activated $\mathrm{T}$ cells or within long-term suppression assays, but do not seem to be involved in resting $\mathrm{T}$ cells. In addition, other NFAT family members may have a dual role in early versus late suppression mechanisms.

\section{Suppression of NF-к B signaling in Tcons downstream of PKC $\boldsymbol{\theta}$}

To our knowledge, except for our report (Schmidt et al., 2011) there are no publications comparing IKK and IК $\mathrm{B} \alpha$ phosphorylation or NF- $\kappa \mathrm{B}$ activation in suppressed and control Tcons. Yet one study showed that Tregs inhibit TLR-induced NF- $\kappa \mathrm{B}$ activation in murine macrophages, suggesting suppression of NF- $\kappa \mathrm{B}$ as a common mechanism of Treg-mediated suppression ( $\mathrm{Li}$ et al., 2010). However, $\mathrm{Li}$ et al. cannot exclude that NF- $\kappa \mathrm{B}$ suppression is a secondary effect due to increased IL-10 and TGF- $\beta$ levels in the suppressed macrophages.

As artificial $\mathrm{Ca}^{2+}$ store depletion could abrogate Treg-mediated suppression, we hypothesize that suppression of $\mathrm{Ca}^{2+}$ signals causes suppression of NF- $\kappa \mathrm{B}$. However, the exact mechanism through which $\mathrm{Ca}^{2+}$ influences NF- $\mathrm{B}$ in T cells and how Tregs interfere here remains to be resolved. Calcineurin, which is activated by $\mathrm{Ca}^{2+}$, synergistically contributes to degradation of Iк $\mathrm{B} \alpha$ when PKC $\theta$ is active (Frantz et al., 1994; Feske, 2007). As shown in Jurkat and primary T cells, this effect is probably due to activation of IKK $\beta$ by calcineurin and PKC $\theta$ (Trushin et al., 1999). The effects of $\mathrm{Ca}^{2+}$ on the CBM complex are less clear and involve positive as well as negative regulation. On the one hand, the $\mathrm{Ca}^{2+}$ :calmodulin-dependent kinase CaMKII was shown to enhance NF- $\kappa \mathrm{B}$ activation by phosphorylation of CARMA1 (Ishiguro et al., 2006) and Bcl-10 (Oruganti et al., 2011). Furthermore, calcineurin was recently reported to enhance CBM complex formation by dephosphorylation of Bcl-10 [at (a) different phosphosite(s)] (Frischbutter et al., 2011; Palkowitsch et al., 2011). On 
the other hand, $\mathrm{Ca}^{2+}:$ calmodulin binding to $\mathrm{Bcl}-10$ was shown to reduce association of Bcl-10 with CARMA1 (Edin et al., 2010). Interestingly, we have indications pointing to an unknown and calcineurin-independent role for IKK in rapid TCR-mediated and $\mathrm{Ca}^{2+}$-dependent NF- $\kappa \mathrm{B}$ activation. In Tcons which were treated with the calcineurin inhibitor cyclosporin A, NFAT activation could be completely abrogated while IKK phosphorylation was not and I $\mathrm{B} \alpha$ phosphorylation was only slightly affected (unpublished observation). In contrast, when we treated Tcons with the $\mathrm{Ca}^{2+}$ chelator EGTA, IKK and I $\mathrm{B} \alpha$ phosphorylation was markedly reduced, similar to what we observe upon coculture with Tregs (Schmidt et al., 2011). Yet calcineurin inhibition might add to NF$\kappa \mathrm{B}$ suppression, as $\mathrm{p} 65$ phosphorylation was shown to be sensitive to calcineurin inhibitors (Frischbutter et al., 2011).

It remains possible that NF- $\kappa \mathrm{B}$ suppression is not only mediated by $\mathrm{Ca}^{2+}$ suppression, but other components of the NF- $\mathrm{B}$ pathway might be inhibited as well. Our data indicate that PKCO activity is unchanged as $\mathrm{PKC} \theta$ (Thr538) phosphorylation was not suppressed. Thr538 phosphorylation is important for PKC activity, interaction with IKK, and NF- $\kappa \mathrm{B}$ activation. This phosphorylation is generated by the kinase GLK, which is activated downstream of the TCR (Chuang et al., 2011), and also involves PDK1 activation downstream of the costimulatory receptor CD28 (Liu et al., 2002; Lee et al., 2005). However, other phosphorylation sites in PKC $\theta$ have been described. Furthermore, PKC $\theta$ might also act upstream of PLC $\gamma$ (Manicassamy et al., 2006a) and may also influence $\mathrm{Ca}^{2+}$ flux though there are controversies in two different studies with PKC $\theta$ deficient mice (Sun et al., 2000; Pfeifhofer et al., 2003; Manicassamy et al., 2006b). It should be subject to further investigations whether PKC $\theta$ recruitment and/or activity or formation of the CBM complex might be changed in suppressed T cells.

Regarding PKC recruitment, one study demonstrated reduced recruitment of $\mathrm{PKC} \theta$ to the immunological synapse in suppressed murine Tcons (Sumoza-Toledo et al., 2006), yet this was only true when the Treg and the Tcon were of the same antigen specificity and had contact to the same APC. Even when a Treg and a Tcon with different antigen specificity had contact to the same APC, which presented both antigens, no suppression of $\mathrm{PKC} \theta$ recruitment was observed. However, findings of Sumoza-Toledo's group are not in accordance with many other studies in that they observed suppression of IL-2 and proliferation only when Treg and Tcon were of the same antigen specificity and had contact to the same APC (Tanchot et al., 2004). We used polyclonal human Tcons and Tregs in the absence of APCs, which represents a different setup than the system used by Sumoza-Toledo et al. and renders it unlikely that suppression of $\mathrm{PKC} \theta$ recruitment is involved in our study regarding direct Treg-mediated rapid cytokine suppression. Accordingly, DAG generation, which is crucial for PKC $\theta$ recruitment, was unaffected in suppressed Tcons (Schmidt et al., 2011).

\section{CONTACT-DEPENDENT CYTOKINE SUPPRESSION IS RETAINED AFTER REMOVAL OF Tregs}

Direct cell contact seemed to be required for suppression of TCR signaling in Tcons, yet the inhibited state of Tcons was sustained after removal of Tregs from the coculture (Schmidt et al., 2011). To be suppressed, Tcons must have had cell contact with pre-activated Tregs for only about $45 \mathrm{~min}$. This implies that Tregs, despite being present in lower numbers than Tcons in vivo, may have the capacity to suppress several Tcons in a sequential fashion. Interestingly, we found that suppression of TCR signaling, IL-2 and IFN- $\gamma$ transcription as well as IFN- $\gamma$ secretion was retained upon Treg removal, while suppression of proliferation was not. Also Sojka et al. (2005) found that murine Tregs can be removed from the coculture with Tcons and still render Tcons suppressed, yet in contrast to our results, suppression of proliferation was observed. However, pre-cocultures were done in the presence of APCs, so additional effects of Tregs on B7 expression of APCs cannot be excluded. Our human Tcon:Treg pre-cocultures were done without APCs for 30-90 min. In the study by Sojka et al., $2 \mathrm{~h}$ of coculture was the shortest time period investigated, which already resulted in approximately $50 \%$ suppression while pre-coculture of $\geq 12 \mathrm{~h}$ resulted in $90 \%$ suppression of proliferation.

\section{SUPPRESSION OF PROLIFERATION VERSUS CYTOKINE PRODUCTION - DIFFERENT MECHANISMS?}

As suggested by others (Tang and Bluestone, 2008), we propose that different mechanisms of suppression might be used by Tregs depending on their activation state, the site of inflammation, effector cell types and point in time of suppression. Furthermore, direct suppression of T cells or indirect suppression via APC inhibition both may be relevant in vivo. Along that line, in addition to suppression of $\mathrm{T}$ cell priming and proliferation through inhibition of APCs by Tregs as described by many groups, direct suppression of $\mathrm{CD}^{+} \mathrm{T}$ cell effector function independently of repressed proliferation in vivo has been described (Mempel et al., 2006), underscoring the relevance of direct $\mathrm{T}$ cell suppression by Tregs. Further, it was shown that Treg-mediated suppression of IFN- $\gamma$ production by $\mathrm{CD} 4{ }^{+} \mathrm{T}$ cells can occur without concomitant suppression of proliferation in vivo (Sojka and Fowell, 2011). However, the importance of direct suppression of TCR signaling and, consequently, rapid suppression of IL- 2 and IFN- $\gamma$ transcription in vivo remains elusive to date.

Our data might suggest that at least three different mechanisms of human Tcon suppression may operate. First, rapid suppression of $\mathrm{Ca}^{2+}$, NFAT, and NF- $\kappa \mathrm{B}$ signaling results in inhibition of cytokine production, which requires Treg pre-activation, is favored by cell contact, retained upon Treg removal and seems to be independent of CTLA-4, APCs, and IL-2 deprivation (Oberle et al., 2007; Schmidt et al., 2011). Second, based on our data, we propose that direct suppression of human Tcon proliferation seems to require prolonged contact to Tregs and may be independent of $\mathrm{Ca}^{2+}$ and cytokine suppression. In line with that, mice with $\mathrm{CD} 4{ }^{+}$ T cell-specific double deficiency of STIM1 and STIM2 display massive $\mathrm{T}$ cell proliferation despite undetectable store-operated $\mathrm{Ca}^{2+}$ influx (Oh-Hora et al., 2008). In addition, a marked decrease in Treg numbers contributes to lymphoproliferation in these mice. However, alternative modes of $\mathrm{Ca}^{2+}$ entry might compensate for the absence of STIM, e.g., $\mathrm{Ca}_{\mathrm{v}}$ calcium channels might operate when their inhibition by STIM1 is lacking (Park et al., 2010; Wang et al., 2010). It remains to be shown whether, despite suppression of IL-2 transcription, residual IL-2 might be sufficient to drive proliferation several days after Treg removal. Depending on the strength of stimulation, IL-2 amounts and, thus, the effect on 
proliferation may differ. Third, suppression of APCs by Tregs via CTLA-4 contributes to suppression of Tcon proliferation in the presence of APCs.

\section{IS CD28 SIGNALING AFFECTED IN Tcons UPON SUPPRESSION BY Tregs?}

Proliferation and activation of T cells does not only require TCR stimulation but also a second, costimulatory signal (Acuto and Michel, 2003). CD28, the most prominent costimulatory receptor, is expressed on naïve and activated $\mathrm{T}$ cells and is triggered by its ligands CD80 and CD86, which are expressed on activated APCs and at low levels on long-term activated T cells. Phosphoinositide 3-kinase (PI3K), which generates phosphatidylinositol 3,4,5-trisphosphate $\left(\mathrm{PIP}_{3}\right)$, is one of the key effectors downstream of CD28 and facilitates activation of PDK1 and one of its targets, the kinase Akt (protein kinase $\mathrm{B}, \mathrm{PKB}$ ). PTEN is a lipid phosphatase that negatively regulates the PI3K/Akt pathway by dephosphorylation of $\mathrm{PIP}_{3}$ into $\mathrm{PIP}_{2}$. TCR-induced activation of the transcription factors AP-1, NFAT, and in particular NF- $\kappa \mathrm{B}$ is directly influenced and amplified by CD28 signaling.

Thus far, the influence of Tregs on CD28 signaling in Tcons is unclear, although several hints from the literature support the hypothesis that Tregs might suppress CD28 signaling in addition to TCR signaling: strong activation or strong CD28 costimulation can (partially) overcome suppression of Tcons by Tregs. This was shown for suppression of IL-2 mRNA and protein as well as for proliferation of murine T cells (Thornton et al., 2004a; Sojka et al., 2005), and also for proliferation and IFN- $\gamma$ secretion of human Tcons (Baecher-Allan et al., 2002), all performed in the presence of APCs. We used CD28 costimulation to achieve detectable phosphorylation of TCR signaling proteins and still observed Tregmediated suppression. Yet, we have indications that suppression of $\mathrm{Ca}^{2+}$ and of proliferation was abrogated upon increasing the strength of stimulation (unpublished observation).

Reversal of Treg-mediated suppression by CD28 costimulation might involve activation of PI3K/Akt, since different studies imply that hyperactivation of the PI3K/Akt pathway renders Tcons resistant to Treg-mediated suppression (Wohlfert and Clark, 2007). For example, T cell-specific TRAF6 deletion led to hyperactivation of the PI3K/Akt pathway, resistance to Treg-mediated suppression and T cell-mediated autoimmune disease (King et al., 2006). However, PI3K/Akt-induced autoimmune disease might also be attributed to impaired CD95-mediated T cell apoptosis (Ohashi and Yeh, 2006). In addition, partial resistance to Treg-mediated suppression was conferred by expression of constitutively active Akt in T cells (Pierau et al., 2009) or PI3K/Akt activation by IL-15 (Ben Ahmed et al., 2009). These authors did not find involvement of apoptosis in contrast to Pandiyan et al. (2007) who claim that Tregs deprive responder Tcons of IL-2 or IL-15 and, thus, reduced Akt activation and survival of murine Tcons was observed. Similarly, a slight downregulation of Akt phosphorylation could be demonstrated in $\mathrm{CD}^{+} \mathrm{T}$ cells upon coculture with Tregs, while ZAP-70 was unaffected (Kojima et al., 2005). Furthermore, it was found that effector $\mathrm{T}$ cells from juvenile arthritis patients are resistant to suppression due to Akt hyperactivation (Wehrens et al., 2011). In addition, Cbl-b knockout T cells are resistant to suppression (Wohlfert et al., 2004), which might involve functions of Cbl-b in anergy as well as its negative influence on CD28/PI3K signaling. Also NFAT1/4 double knockout T cells, which are partially resistant to suppression (Bopp et al., 2005), do not require CD28 costimulation to be activated (Ranger et al., 1998), suggesting PI3K/Akt hyperactivation in these cells.

Since the PI3K/Akt pathway crosstalks with all main TCR signaling pathways, it might be involved in Treg-mediated rapid suppression. It remains to be analyzed whether hyperactivation of the PI3K/Akt pathway also abrogates Treg-mediated suppression of $\mathrm{Ca}^{2+}$, NF- $\kappa \mathrm{B}$, and NFAT. Further, it remains to be shown whether Tregs might act via inhibition of PI3K/Akt signaling in human Tcons. However, it is unclear how this would directly translate into reduced $\mathrm{Ca}^{2+}$ store depletion without concomitant reduction of, e.g., PLC $\gamma$ activity. Analyses of known and unknown pathways downstream of CD28 in Tcons upon suppression by Tregs remain subject to further investigation.

\section{CONCLUDING REMARIKS}

A growing body of evidence indicates that Tregs do not use only one universal mechanism of suppression, but rather an arsenal of different ones. So far, it is unclear how a Treg "decides" which mechanism to apply, and whether it can switch from one to the other and/or apply several modes of suppression simultaneously. Mechanisms of suppression as well as target $\mathrm{T}$ cell susceptibility to suppression likely differ depending on tissue site, cell types involved and activation status of target cell and Treg. Furthermore, different Treg subsets exist and further research should reveal whether these are specialized on a particular suppressive mechanism.

In the commonly used in vitro suppression assays, not all aspects of suppression can be detected with a single readout or point in time, as suppression of proliferation does not necessarily reflect suppression of effector cytokine production. In addition, effects of Tregs on APCs have to be addressed if these are included in the assay. Furthermore, it was shown by several groups that Tregs have to be TCR-activated in order to be suppressive, which might be particularly important for assays assessing rapid suppression and, thus, leaving little time for the Tregs to get activated during stimulation of the coculture. Therefore, it is important to control for potential effects of the pre-activating reagent itself. A possible control for effects of the pre-activating reagent is the use of pre-activated Tcons in comparison with pre-activated Tregs, however, human pre-activated Tcons themselves might upregulate Foxp3 and/or acquire suppressive function. Another possibility is the use of pre-activating reagents which can be removed completely after Treg pre-activation, such as covalently platebound anti-CD3 antibodies.

The knowledge of molecules and signaling pathways affected in Tcons upon suppression by Tregs might be crucial for their therapeutic manipulation in the future. In cancer, suppression of effector $\mathrm{T}$ cells is deleterious and breaking the suppressive state is highly desirable. In contrast, a suppressed state of autoreactive $\mathrm{T}$ cells is warranted during autoimmune disease. Further research is required to elucidate which mechanisms of Tregmediated suppression or of target $\mathrm{T}$ cell resistance to suppression are most important in a particular disease, and possible therapeutic interventions have to be performed extremely carefully. 


\section{ACKNOWLEDGMENTS}

We thank Rüdiger Arnold, Heinke Conrad, Thomas Mock, and David Richards for discussions and critical reading of the manuscript. Our work was supported by: Contract research "Forschungsprogramm Allergologie II” of the Baden-Württemberg Stiftung

\section{REFERENCES}

Abbracchio, M. P., Burnstock, G., Boeynaems, J. M., Barnard, E. A., Boyer, J. L., Kennedy, C., Knight, G. E., Fumagalli, M., Gachet, C., Jacobson, K. A., and Weisman, G. A. (2006). International Union of Pharmacology LVIII: update on the P2Y G proteincoupled nucleotide receptors: from molecular mechanisms and pathophysiology to therapy. Pharmacol. Rev. 58, 281-341.

Acuto, O., and Michel, F. (2003). CD28mediated co-stimulation: a quantitative support for TCR signalling. Nat. Rev. Immunol. 3, 939-951.

Ahern, P. P., Schiering, C., Buonocore, S., McGeachy, M. J., Cua, D. J., Maloy, K. J., and Powrie, F. (2010). Interleukin23 drives intestinal inflammation through direct activity on $\mathrm{T}$ cells. Immunity 33, 279-288.

Allan, S. E., Crome, S. Q., Crellin, N. K., Passerini, L., Steiner, T. S., Bacchetta, R., Roncarolo, M. G., and Levings, M. K. (2007). Activationinduced FOXP3 in human $\mathrm{T}$ effector cells does not suppress proliferation or cytokine production. Int. Immunol. 19, 345-354.

Allan, S. E., Song-Zhao, G. X., Abraham, T., McMurchy, A. N., and Levings, M. K. (2008). Inducible reprogramming of human $\mathrm{T}$ cells into Treg cells by a conditionally active form of FOXP3. Eur. J. Immunol. 38, 3282-3289.

Andersson, J., Tran, D. Q., Pesu, M., Davidson, T. S., Ramsey, H., O’Shea, J. J., and Shevach, E. M. (2008). $\mathrm{CD} 4+$ FoxP3 + regulatory $\mathrm{T}$ cells confer infectious tolerance in a TGFbeta-dependent manner. J. Exp. Med. 205, 1975-1981.

Asseman, C., Mauze, S., Leach, M. W., Coffman, R. L., and Powrie, F. (1999). An essential role for interleukin 10 in the function of regulatory $\mathrm{T}$ cells that inhibit intestinal inflammation. J. Exp. Med. 190, 995-1004.

Asseman, C., Read, S., and Powrie, F. (2003). Colitogenic Th1 cells are present in the antigen-experienced $\mathrm{T}$ cell pool in normal mice: control by CD4+ regulatory T cells and IL- 10 . J. Immunol. 171, 971-978.

Baatar, D., Olkhanud, P. B., Wells, V., Indig, F. E., Mallucci, L., and Biragyn, A. (2009). Tregs utilize betagalactoside-binding protein to transiently inhibit PI3K/p21ras activity of human CD8+ $\mathrm{T}$ cells to block their TCR-mediated ERK activity and proliferation. Brain Behav. Immun. 23, 1028-1037.

Bachmann, M. F., Kohler, G., Ecabert, B., Mak, T. W., and Kopf, M. (1999). Cutting edge: lymphoproliferative disease in the absence of CTLA-4 is not $\mathrm{T}$ cell autonomous. J. Immunol. 163, 1128-1131.

Baecher-Allan, C., Brown, J. A., Freeman, G. J., and Hafler, D. A. (2001). CD4+CD25high regulatory cells in human peripheral blood. $J$. Immunol. 167, 1245-1253.

Baecher-Allan, C., Viglietta, V., and Hafler, D. A. (2002). Inhibition of human CD4(+)CD25(+high) regulatory $\mathrm{T}$ cell function. J. Immunol. 169, 6210-6217.

Baecher-Allan, C., Wolf, E., and Hafler, D. A. (2006). MHC class II expression identifies functionally distinct human regulatory $\mathrm{T}$ cells. $J$. Immunol. 176, 4622-4631.

Bandyopadhyay, S., Soto-Nieves, N., and Macian, F. (2007). Transcriptional regulation of T cell tolerance. Semin. Immunol. 19, 180-187.

Bardel, E., Larousserie, F., CharlotRabiega, P., Coulomb-L'Hermine, A., and Devergne, O. (2008). Human CD4+ CD25+ Foxp3+ regulatory $\mathrm{T}$ cells do not constitutively express IL-35. J. Immunol. 181, 6898-6905.

Barthlott, T., Moncrieffe, H., Veldhoen, M., Atkins, C. J., Christensen, J., O'Garra, A., and Stockinger, B. (2005). CD25+ CD4+ T cells compete with naive CD4+ T cells for IL-2 and exploit it for the induction of IL-10 production. Int. Immunol. 17, 279-288.

Bazhin, A. V., Kahnert, S., Kimpfler, V. (2010). Distinct metabolism of cyclic adenosine monophosphate in regulatory and helper CD4+ T cells. Mol. Immunol. 47, 678-684.

Belkaid, Y. (2007). Regulatory T cells and infection: a dangerous necessity. Nat. Rev. Immunol. 7, 875-888.

Ben Ahmed, M., Belhadj, H. N., Moes, N., Buyse, S., Abdeladhim, M., Louzir, H., and Cerf-Bensussan, N. (2009). IL-15 renders conventional lymphocytes resistant to suppressive functions of regulatory $\mathrm{T}$ cells phatidylinositol 3-kinase pathway. J. Immunol. 182, 6763-6770.

Beriou, G., Costantino, C. M., Ashley, C. W., Yang, L., Kuchroo, V. S., Schadendorf, D., and Umansky, through activation of the phos-

(P-LS-AL-18/2); Alliance for Immunotherapy of the Helmholtz Society; SFB 405; Ph.D. Fellowship of the Helmholtz International Graduate School for Cancer Research at the DKFZ (to Angelika Schmidt). We apologize to all authors whose work could not be cited due to space limitations.

K., Baecher-Allan, C., and Hafler, D. A. (2009). IL-17-producing human peripheral regulatory $\mathrm{T}$ cells retain suppressive function. Blood 113 4240-4249.

Beyer, M., and Schultze, J. L. (2007). CD4+CD25highFOXP3+ regulatory $\mathrm{T}$ cells in peripheral blood are primarily of effector memory phenotype. J. Clin. Oncol. 25, 2628-2630.

Birebent, B., Lorho, R., Lechartier, H., de Guibert, S., Alizadeh, M., Vu, N. Beauplet, A., Robillard, N., and Semana, G. (2004). Suppressive properties of human CD4+CD25+ regulatory $\mathrm{T}$ cells are dependent on CTLA4 expression. Eur. J. Immunol. 34, 3485-3496.

Bodor, J., Bodorova, J., and Gress, R. E. (2000). Suppression of T cell function: a potential role for transcriptional repressor ICER. J. Leukoc. Biol. 67, 774-779.

Bodor, J., Fehervari, Z., Diamond, B., and Sakaguchi, S. (2007a). ICER/CREM-mediated transcriptional attenuation of IL-2 and its role in suppression by regulatory $\mathrm{T}$ cells. Eur. J. Immunol. 37, 884-895.

Bodor, J., Fehervari, Z., Diamond, B. and Sakaguchi, S. (2007b). Regulatory $\mathrm{T}$ cell-mediated suppression: potential role of ICER. J. Leukoc. Biol. 81, 161-167.

Bopp, T., Becker, C., Klein, M., KleinHessling, S., Palmetshofer, A., Serfling, E., Heib, V., Becker, M., Kubach, J., Schmitt, S., Stoll, S., Schild, H., Staege, M. S., Stassen, M., Jonuleit, H., and Schmitt, E. (2007). Cyclic adenosine monophosphate is a key component of regulatory $\mathrm{T}$ cell-mediated suppression. J. Exp. Med. 204, 1303-1310.

Bopp, T., Palmetshofer, A., Serfling, E., Heib, V., Schmitt, S., Richter, C., Klein, M., Schild, H., Schmitt, E., and Stassen, M. (2005). NFATc2 and NFATc3 transcription factors play a crucial role in suppression of CD4+ T lymphocytes by CD4+ CD25+ regulatory T cells. J. Exp. Med. 201, 181-187.

Borsellino, G., Kleinewietfeld, M., Di, M. D., Sternjak, A., Diamantini, A., Giometto, R., Hopner, S., Centonze, D., Bernardi, G., Dell'Acqua, M. L., Rossini, P. M., Battistini, L., Rotzschke, O., and Falk, K. (2007). Expression of ectonucleotidase CD39 by Foxp3+ Treg cells: hydrolysis of extracellular ATP and immune suppression. Blood 110, 1225-1232.

Buckner, J. H. (2010). Mechanisms of impaired regulation by $\mathrm{CD} 4(+) \mathrm{CD} 25(+)$ FOXP3(+) regulatory $\mathrm{T}$ cells in human autoimmune diseases. Nat. Rev. Immunol. 10, 849-859.

Cao, X., Cai, S. F., Fehniger, T. A., Song, J., Collins, L. I., Piwnica-Worms, D. R., and Ley, T. J. (2007). Granzyme B and perforin are important for regulatory $\mathrm{T}$ cell-mediated suppression of tumor clearance. Immunity 27, 635-646.

Cederbom, L., Hall, H., and Ivars, F. (2000). CD4+CD25+ regulatory $\mathrm{T}$ cells down-regulate costimulatory molecules on antigenpresenting cells. Eur. J. Immunol. 30, 1538-1543.

Chaturvedi, V., Collison, L. W., Guy, C. S., Workman, C. J., and Vignali, D. A. (2011). Cutting edge: human regulatory $\mathrm{T}$ cells require IL- 35 to mediate suppression and infectious tolerance. J. Immunol. 186, 6661-6666.

Chaudhry, A., Rudra, D., Treuting, P., Samstein, R. M., Liang, Y., Kas, A., and Rudensky, A. Y. (2009). CD4+ regulatory $\mathrm{T}$ cells control $\mathrm{TH} 17$ responses in a Stat3-dependent manner. Science 326, 986-991.

Chaudhry, A., Samstein, R. M., Treuting, P., Liang, Y., Pils, M. C., Heinrich, J. M., Jack, R. S., Wunderlich, F. T., Bruning, J. C., Muller, W., and Rudensky, A. Y. (2011). Interleukin10 signaling in regulatory $\mathrm{T}$ cells is required for suppression of Th17 cell-mediated inflammation. Immunity 34, 566-578.

Chauhan, S. K., El Annan, J., Ecoiffier, T., Goyal, S., Zhang, Q., Saban, D. R., and Dana, R. (2009). Autoimmunity in dry eye is due to resistance of Th17 to Treg suppression. J. Immunol. 182, 1247-1252.

Chinenov, Y., and Kerppola, T. K. (2001). Close encounters of many kinds: Fos-Jun interactions that mediate transcription regulatory specificity. Oncogene 20, 2438-2452.

Chuang, H. C., Lan, J. L., Chen, D. Y., Yang, C. Y., Chen, Y. M., Li, J. P., Huang, C. Y., Liu, P. E., Wang, X., and Tan, T. H. (2011). The kinase GLK controls autoimmunity and NF-kappaB signaling by activating the kinase PKC-theta in T cells. Nat. Immunol. 12, 1113-1118. 
Collison, L. W., Chaturvedi, V., Henderson, A. L., Giacomin, P. R., Guy, C., Bankoti, J., Finkelstein, D., Forbes, K., Workman, C. J., Brown, S. A., Rehg, J. E., Jones, M. L., Ni, H. T., Artis, D., Turk, M. J., and Vignali, D. A. (2010). IL-35-mediated induction of a potent regulatory $\mathrm{T}$ cell population. Nat. Immunol. 11, 1093-1101.

Collison, L. W., Workman, C. J., Kuo, T. T., Boyd, K., Wang, Y., Vignali, K. M., Cross, R., Sehy, D., Blumberg, R. S., and Vignali, D. A. (2007). The inhibitory cytokine IL-35 contributes to regulatory T-cell function. Nature 450, 566-569.

Curiel, T. J. (2008). Regulatory T cells and treatment of cancer. Curr. Opin. Immunol. 20, 241-246.

Curotto de Lafaille, M. A., and Lafaille, J. J. (2009). Natural and adaptive foxp3+ regulatory $\mathrm{T}$ cells: more of the same or a division of labor? Immunity 30, 626-635.

Curti, A., Pandolfi, S., Valzasina, B., Aluigi, M., Isidori, A., Ferri, E., Salvestrini, V., Bonanno, G., Rutella, S., Durelli, I., Horenstein, A. L., Fiore, F., Massaia, M., Colombo, M. P., Baccarani, M., and Lemoli, R. M. (2007). Modulation of tryptophan catabolism by human leukemic cells results in the conversion of $\mathrm{CD} 25$ into CD25+ T regulatory cells. Blood 109, 2871-2877.

de la Rosa, M., Rutz, S., Dorninger, H., and Scheffold, A. (2004). Interleukin-2 is essential for $\mathrm{CD} 4+\mathrm{CD} 25+$ regulatory $\mathrm{T}$ cell function. Eur. J. Immunol. 34, 2480-2488.

Deaglio, S., Dwyer, K. M., Gao, W., Friedman, D., Usheva, A., Erat, A., Chen, J. F., Enjyoji, K., Linden, J., Oukka, M., Kuchroo, V. K., Strom, T. B., and Robson, S. C. (2007). Adenosine generation catalyzed by CD39 and $\mathrm{CD} 73$ expressed on regulatory $\mathrm{T}$ cells mediates immune suppression. J. Exp. Med. 204, 1257-1265.

Dieckmann, D., Plottner, H., Berchtold, S., Berger, T., and Schuler, G. (2001). Ex vivo isolation and characterization of CD4(+)CD25(+) T cells with regulatory properties from human blood. J. Exp. Med. 193, 1303-1310.

Dong, C., Davis, R. J., and Flavell, R. A. (2002). MAP kinases in the immune response. Annu. Rev. Immunol. 20, 55-72.

Durant, L., Watford, W. T., Ramos, H. L., Laurence, A., Vahedi, G., Wei, L., Takahashi, H., Sun, H. W., Kanno, Y., Powrie, F., and O'Shea, J. J. (2010). Diverse targets of the transcription factor STAT3 contribute to T cell pathogenicity and homeostasis. Immunity 32, 605-615.

Edin, S., Oruganti, S. R., Grundstrom, C., and Grundstrom, T. (2010). Interaction of calmodulin with Bcl10 modulates NF-kappaB activation. Mol. Immunol. 47, 2057-2064.

Ermann, J., Szanya, V., Ford, G. S., Paragas, V., Fathman, C. G., and Lejon, K. (2001). CD4(+)CD25(+) T cells facilitate the induction of $\mathrm{T}$ cell anergy. J. Immunol. 167, 4271-4275.

Ernst, P. B., Garrison, J. C., and Thompson, L. F. (2010). Much ado about adenosine: adenosine synthesis and function in regulatory $\mathrm{T}$ cell biology. J. Immunol. 185, 1993-1998.

Esquerre, M., Tauzin, B., Guiraud, M., Muller, S., Saoudi, A., and Valitutti, S. (2008). Human regulatory T cells inhibit polarization of $\mathrm{T}$ helper cells toward antigen-presenting cells via a TGF-beta-dependent mechanism. Proc. Natl. Acad. Sci. U.S.A. 105, 2550-2555.

Fahlen, L., Read, S., Gorelik, L., Hurst, S. D., Coffman, R. L., Flavell, R. A., and Powrie, F. (2005). T cells that cannot respond to TGF-beta escape control by $\mathrm{CD} 4(+) \mathrm{CD} 25(+)$ regulatory $\mathrm{T}$ cells. J. Exp. Med. 201, 737-746.

Fallarino, F., Grohmann, U., Hwang, K. W., Orabona, C., Vacca, C., Bianchi, R., Belladonna, M. L., Fioretti, M. C., Alegre, M. L., and Puccetti, P. (2003). Modulation of tryptophan catabolism by regulatory T cells. Nat. Immunol. 4, 1206-1212.

Fallarino, F., Grohmann, U., You, S., McGrath, B. C., Cavener, D. R., Vacca, C., Orabona, C., Bianchi, R., Belladonna, M. L., Volpi, C., Santamaria, P., Fioretti, M. C., and Puccetti, P. (2006). The combined effects of tryptophan starvation and tryptophan catabolites downregulate $\mathrm{T}$ cell receptor zeta-chain and induce a regulatory phenotype in naive T cells. J. Immunol. 176, 6752-6761.

Fassbender, M., Gerlitzki, B., Ullrich, N., Lupp, C., Klein, M., Radsak, M. P., Schmitt, E., Bopp, T., and Schild, H. (2010). Cyclic adenosine monophosphate and IL-10 coordinately contribute to nTreg cellmediated suppression of dendritic cell activation. Cell. Immunol. 265, 91-96.

Feske, S. (2007). Calcium signalling in lymphocyte activation and disease. Nat. Rev. Immunol. 7, 690-702.

Feske, S., Prakriya, M., Rao, A., and Lewis, R. S. (2005). A severe defect in CRAC Ca2 + channel activation and altered $\mathrm{K}+$ channel gating in $\mathrm{T}$ cells from immunodeficient patients. $J$. Exp. Med. 202, 651-662.
Feuerer, M., Hill, J. A., Kretschmer, K. von Boehmer, H., Mathis, D., and Benoist, C. (2010). Genomic definition of multiple ex vivo regulatory $\mathrm{T}$ cell subphenotypes. Proc. Natl. Acad. Sci. U.S.A. 107, 5919-5924.

Feuerer, M., Hill, J. A., Mathis, D. and Benoist, C. (2009). Foxp3+ regulatory $\mathrm{T}$ cells: differentiation, specification, subphenotypes. Nat. Immunol. 10, 689-695.

Fontenot, J. D., Gavin, M. A., and Rudensky, A. Y. (2003). Foxp3 programs the development and function of CD4+CD25+ regulatory $\mathrm{T}$ cells. Nat. Immunol. 4, 330-336.

Franke, A., Balschun, T., Karlsen, T. H., Sventoraityte, J., Nikolaus, S., Mayr, G., Domingues, F. S., Albrecht, M., Nothnagel, M., Ellinghaus, D., Sina, C., Onnie, C. M., Weersma, R. K., Stokkers, P. C., Wijmenga, C., Gazouli, M., Strachan, D., McArdle, W. L., Vermeire, S., Rutgeerts, P., Rosenstiel, P., Krawczak, M., Vatn, M. H., Mathew, C. G., and Schreiber, S. (2008). Sequence variants in IL10, ARPC2 and multiple other loci contribute to ulcerative colitis susceptibility. Nat. Genet. 40, 1319-1323.

Frantz, B., Nordby, E. C., Bren, G. Steffan, N., Paya, C. V., Kincaid, R. L., Tocci, M. J., O'Keefe, S. J., and O'Neill, E. A. (1994). Calcineurin acts in synergy with PMA to inactivate I kappa B/MAD3, an inhibitor of NF-kappa B. EMBO J. 13, 861-870.

Friedline, R. H., Brown, D. S., Nguyen, H., Kornfeld, H., Lee, J., Zhang, Y., Appleby, M., Der, S. D., Kang, J., and Chambers, C. A. (2009). CD4+ regulatory $\mathrm{T}$ cells require CTLA4 for the maintenance of systemic tolerance. J. Exp. Med. 206, 421-434.

Frischbutter, S., Gabriel, C., Bendfeldt, H., Radbruch, A., and Baumgrass, R. (2011). Dephosphorylation of $\mathrm{Bcl}-10$ by calcineurin is essential for canonical NF-kappaB activation in Th cells. Eur. J. Immunol. 41, 2349-2357.

Gasser, A., Bruhn, S., and Guse, A. H. (2006). Second messenger function of nicotinic acid adenine dinucleotide phosphate revealed by an improved enzymatic cycling assay. $J$. Biol. Chem. 281, 16906-16913.

Gavin, M. A., Torgerson, T. R., Houston, E., DeRoos, P., Ho, W. Y., StrayPedersen, A., Ocheltree, E. L., Greenberg, P. D., Ochs, H. D., and Rudensky, A. Y. (2006). Single-cell analysis of normal and FOXP3-mutant human T cells: FOXP3 expression without regulatory $\mathrm{T}$ cell development. Proc. Natl. Acad. Sci. U.S.A. 103, 6659-6664.
Gershon, R. K., and Kondo, K. (1970). Cell interactions in the induction of tolerance: the role of thymic lymphocytes. Immunology 18, 723-737.

Glocker, E. O., Kotlarz, D., Boztug, K., Gertz, E. M., Schaffer, A. A., Noyan, F., Perro, M., Diestelhorst, J., Allroth, A., Murugan, D., Hatscher, N., Pfeifer, D., Sykora, K. W., Sauer, M., Kreipe, H., Lacher, M., Nustede, R., Woellner, C., Baumann, U., Salzer, U., Koletzko, S., Shah, N., Segal, A. W., Sauerbrey, A., Buderus, S., Snapper, S. B., Grimbacher, B., and Klein, C. (2009). Inflammatory bowel disease and mutations affecting the interleukin-10 receptor. N. Engl. J. Med. 361, 2033-2045.

Godfrey, W. R., Spoden, D. J., Ge, Y. G., Baker, S. R., Liu, B., Levine, B. L., June, C. H., Blazar, B. R., and Porter, S. B. (2005). Cord blood CD4(+)CD25(+)-derived T regulatory cell lines express FoxP3 protein and manifest potent suppressor function. Blood 105, 750-758.

Gondek, D. C., Devries, V., Nowak, E. C., Lu, L. F., Bennett, K. A., Scott, Z. A., and Noelle, R. J. (2008). Transplantation survival is maintained by granzyme $\mathrm{B}+$ regulatory cells and adaptive regulatory $\mathrm{T}$ cells. $J$. Immunol. 181, 4752-4760.

Gondek, D. C., Lu, L. F., Quezada, S. A., Sakaguchi, S., and Noelle, R. J. (2005). Cutting edge: contact-mediated suppression by $\mathrm{CD} 4+\mathrm{CD} 25+$ regulatory cells involves a granzyme B-dependent, perforin-independent mechanism. J. Immunol. 174, 1783-1786.

Gounaris, E., Blatner, N. R., Dennis, K., Magnusson, F., Gurish, M. F., Strom, T. B., Beckhove, P., Gounari, F., and Khazaie, K. (2009). Tregulatory cells shift from a protective anti-inflammatory to a cancerpromoting proinflammatory phenotype in polyposis. Cancer Res. 69, 5490-5497.

Grafton, G., and Thwaite, L. (2001). Calcium channels in lymphocytes. Immunology 104, 119-126.

Gri, G., Piconese, S., Frossi, B., Manfroi, V., Merluzzi, S., Tripodo, C., Viola, A., Odom, S., Rivera, J., Colombo, M. P., and Pucillo, C. E. (2008). CD4+CD25+ regulatory $\mathrm{T}$ cells suppress mast cell degranulation and allergic responses through OX40OX40L interaction. Immunity 29, 771-781.

Grossman, W. J., Verbsky, J. W., Barchet, W., Colonna, M., Atkinson, J. P., and Ley, T. J. (2004). Human T regulatory cells can use the perforin pathway to cause autologous target cell death. Immunity 21, 589-601. 
Guse, A. H., da Silva, C. P., Berg, I., Skapenko, A. L., Weber, K., Heyer, P., Hohenegger, M., Ashamu, G. A., Schulze-Koops, H., Potter, B. V., and Mayr, G. W. (1999). Regulation of calcium signalling in $\mathrm{T}$ lymphocytes by the second messenger cyclic ADPribose. Nature 398, 70-73.

Hanig, J., and Lutz, M. B. (2008). Suppression of mature dendritic cell function by regulatory $\mathrm{T}$ cells in vivo is abrogated by CD40 licensing. $J$. Immunol. 180, 1405-1413.

Hermann-Kleiter, N., and Baier, G. (2010). NFAT pulls the strings during $\mathrm{CD} 4+\mathrm{T}$ helper cell effector functions. Blood 115, 2989-2997.

Hoffmann, P., Eder, R., Boeld, T. J., Doser, K., Piseshka, B., Andreesen, R., and Edinger, M. (2006). Only the CD45RA+ subpopulation of $\mathrm{CD} 4+\mathrm{CD} 25$ high $\mathrm{T}$ cells gives rise to homogeneous regulatory $\mathrm{T}$-cell lines upon in vitro expansion. Blood 108, 4260-4267.

Hori, S., Nomura, T., and Sakaguchi, S. (2003). Control of regulatory $\mathrm{T}$ cell development by the transcription factor Foxp3. Science 299, 1057-1061.

Huang, C. T., Workman, C. J., Flies, D., Pan, X., Marson, A. L., Zhou, G., Hipkiss, E. L., Ravi, S., Kowalski, J., Levitsky, H. I., Powell, J. D., Pardoll, D. M., Drake, C. G., and Vignali, D. A. (2004). Role of LAG-3 in regulatory $\mathrm{T}$ cells. Immunity 21 , 503-513.

Huber, M., Steinwald, V., Guralnik, A., Brustle, A., Kleemann, P., Rosenplanter, C., Decker, T., and Lohoff, M. (2008). IL-27 inhibits the development of regulatory $\mathrm{T}$ cells via STAT3. Int. Immunol. 20, 223-234.

Huber, S., Gagliani, N., Esplugues, E., O'Connor, W. Jr., Huber, F. J., Chaudhry, A., Kamanaka, M., Kobayashi, Y., Booth, C. J., Rudensky, A. Y., Roncarolo, M. G., Battaglia, M., and Flavell, R. A. (2011). Th17 cells express interleukin-10 receptor and are controlled by Foxp 3 and Foxp3+ regulatory CD4+ T cells in an interleukin-10-dependent manner. Immunity 34, 554-565.

Isakov, N., and Altman, A. (2002). Protein kinase $\mathrm{C}$ (theta) in $\mathrm{T}$ cell activation. Annu. Rev. Immunol. 20, 761-794.

Ishiguro, K., Green, T., Rapley, J., Wachtel, H., Giallourakis, C., Landry, A., Cao, Z., Lu, N., Takafumi, A., Goto, H., Daly, M. J., and Xavier, R. J. (2006). Ca2+/calmodulindependent protein kinase II is a modulator of CARMA1-mediated NF-kappaB activation. Mol. Cell. Biol. 26, 5497-5508.
Izcue, A., Coombes, J. L., and Powrie, F. (2009). Regulatory lymphocytes and intestinal inflammation. Annu. Rev. Immunol. 27, 313-338.

Jain, J., Loh, C., and Rao, A. (1995). Transcriptional regulation of the IL2 gene. Curr. Opin. Immunol. 7, 333-342.

Jain, J., McCaffrey, P. G., Miner, Z., Kerppola, T. K., Lambert, J. N., Verdine, G. L., Curran, T., and Rao, A. (1993). The T-cell transcription factor NFATp is a substrate for calcineurin and interacts with Fos and Jun. Nature 365, 352-355.

Johnson, G. L., and Lapadat, R. (2002). Mitogen-activated protein kinase pathways mediated by ERK, JNK, and $\mathrm{p} 38$ protein kinases. Science 298 , 1911-1912.

Jonuleit, H., Schmitt, E., Kakirman, H., Stassen, M., Knop, J., and Enk, A. H. (2002). Infectious tolerance: human $\mathrm{CD} 25(+)$ regulatory $\mathrm{T}$ cells convey suppressor activity to conventional CD4(+) T helper cells. J. Exp. Med. 196, 255-260.

Jonuleit, H., Schmitt, E., Stassen, M., Tuettenberg, A., Knop, J., and Enk, A. H. (2001). Identification and functional characterization of human $\mathrm{CD} 4(+) \mathrm{CD} 25(+) \mathrm{T}$ cells with regulatory properties isolated from peripheral blood. J. Exp. Med. 193, 1285-1294.

Kamanaka, M., Huber, S., Zenewicz, L. A., Gagliani, N., Rathinam, C., O'Connor, W. Jr., Wan, Y. Y., Nakae, S., Iwakura, Y., Hao, L., and Flavell, R. A. (2011). Memory/effector (CD45RB(lo)) CD4 T cells are controlled directly by IL- 10 and cause IL-22-dependent intestinal pathology. J. Exp. Med. 208, 1027-1040.

Karim, M., Feng, G., Wood, K. J., and Bushell, A. R. (2005). CD25+CD4+ regulatory $\mathrm{T}$ cells generated by exposure to a model protein antigen prevent allograft rejection: antigenspecific reactivation in vivo is critical for bystander regulation. Blood 105, 4871-4877.

Khattri, R., Cox, T., Yasayko, S. A., and Ramsdell, F. (2003). An essential role for Scurfin in CD4+CD25+ T regulatory cells. Nat. Immunol. 4 , 337-342.

King, C. G., Kobayashi, T., Cejas, P. J., Kim, T., Yoon, K., Kim, G. K., Chiffoleau, E., Hickman, S. P., Walsh, P. T., Turka, L. A., and Choi, Y. (2006). TRAF6 is a T cell-intrinsic negative regulator required for the maintenance of immune homeostasis. Nat. Med. 12, 1088-1092.

Klein, L., Khazaie, K., and von Boehmer, H. (2003). In vivo dynamics of antigen-specific regulatory $\mathrm{T}$ cells not predicted from behavior in vitro. Proc. Natl. Acad. Sci. U.S.A. 100, 8886-8891.

Kobie, J. J., Shah, P. R., Yang, L., Rebhahn, J. A., Fowell, D. J., and Mosmann, T. R. (2006). T regulatory and primed uncommitted CD4 T cells express CD73, which suppresses effector CD4 $\mathrm{T}$ cells by converting $5^{\prime}$-adenosine monophosphate to adenosine. J. Immunol. 177, 6780-6786.

Koch, M. A., Tucker-Heard, G., Perdue, N. R., Killebrew, J. R., Urdahl, K. B., and Campbell, D. J. (2009). The transcription factor T-bet controls regulatory $\mathrm{T}$ cell homeostasis and function during type 1 inflammation. Nat. Immunol. 10, 595-602.

Koenen, H. J., Smeets, R. L., Vink, P. M., van Rijssen, E., Boots, A. M., and Joosten, I. (2008). Human CD25highFoxp3pos regulatory $\mathrm{T}$ cells differentiate into IL-17-producing cells. Blood 112, 2340-2352.

Kojima, H., Kanno, Y., Hase, H., and Kobata, T. (2005). CD4+CD25+ regulatory $\mathrm{T}$ cells attenuate the phosphatidylinositol 3-kinase/Akt pathway in antigen-primed immature CD8+ CTLs during functional maturation. J. Immunol. 174, 5959-5967.

Krummel, M. F., and Allison, J. P. (1996). CTLA-4 engagement inhibits IL-2 accumulation and cell cycle progression upon activation of resting $\mathrm{T}$ cells. J. Exp. Med. 183, 2533-2540.

Kuhn, R., Lohler, J., Rennick, D., Rajewsky, K., and Muller, W. (1993). Interleukin-10-deficient mice develop chronic enterocolitis. Cell 75, 263-274.

Lee, K. Y., D'Acquisto, F., Hayden, M. S., Shim, J. H., and Ghosh, S. (2005). PDK1 nucleates $\mathrm{T}$ cell receptor-induced signaling complex for NF-kappaB activation. Science 308, 114-118.

Lee, Y. K., Mukasa, R., Hatton, R. D., and Weaver, C. T. (2009). Developmental plasticity of Th17 and Treg cells. Curr. Opin. Immunol. 21, 274-280.

Levings, M. K., Sangregorio, R., and Roncarolo, M. G. (2001). Human cd25(+)cd4(+) t regulatory cells suppress naive and memory $\mathrm{T}$ cell proliferation and can be expanded in vitro without loss of function. $J$. Exp. Med. 193, 1295-1302.

Levings, M. K., Sangregorio, R., Sartirana, C., Moschin, A. L., Battaglia, M., Orban, P. C., and Roncarolo, M. G. (2002). Human CD25+CD4+ $\mathrm{T}$ suppressor cell clones produce transforming growth factor beta, but not interleukin 10 , and are distinct from type $1 \mathrm{~T}$ regulatory cells. J. Exp. Med. 196, 1335-1346.

Li, M., Lin, J., Wang, Z., He, S., Ma, X., and Li, D. (2010). Oxidized lowdensity lipoprotein-induced proinflammatory cytokine response in macrophages are suppressed by CD4CD25(+)Foxp3(+) regulatory $\mathrm{T}$ cells through downregulating toll like receptor 2-mediated activation of NF-kappaB. Cell. Physiol. Biochem. 25, 649-656.

Li, M. O., Sanjabi, S., and Flavell, R. A. (2006a). Transforming growth factor-beta controls development, homeostasis, and tolerance of $\mathrm{T}$ cells by regulatory $\mathrm{T}$ cell-dependent and -independent mechanisms. Immunity $25,455-471$.

Li, M. O., Wan, Y. Y., Sanjabi, S., Robertson, A. K., and Flavell, R. A. (2006b). Transforming growth factor-beta regulation of immune responses. Annu. Rev. Immunol. 24, 99-146.

Li, M. O., Wan, Y. Y., and Flavell, R. A. (2007). T cell-produced transforming growth factor-betal controls $\mathrm{T}$ cell tolerance and regulates Th1- and Th17-cell differentiation. Immunity 26, 579-591.

Li, Q., and Verma, I. M. (2002). NFkappaB regulation in the immune system. Nat. Rev. Immunol. 2, 725-734.

Liang, B., Workman, C., Lee, J., Chew, C. Dale, B. M., Colonna, L., Flores, M., Li, N., Schweighoffer, E., Greenberg, S., Tybulewicz, V., Vignali, D., and Clynes, R. (2008). Regulatory T cells inhibit dendritic cells by lymphocyte activation gene- 3 engagement of MHC class II. J. Immunol. 180, 5916-5926.

Lin, J., and Weiss, A. (2001). T cell receptor signalling. J. Cell. Sci. 114, 243-244.

Liu, Y., Graham, C., Li, A., Fisher, R. J., and Shaw, S. (2002). Phosphorylation of the protein kinase Ctheta activation loop and hydrophobic motif regulates its kinase activity, but only activation loop phosphorylation is critical to in vivo nuclearfactor-kappaB induction. Biochem. J. 361, 255-265.

Lochner, M., Peduto, L., Cherrier, M., Sawa, S., Langa, F., Varona, R., Riethmacher, D., Si-Tahar, M., Di Santo, J. P., and Eberl, G. (2008). In vivo equilibrium of proinflammatory IL$17+$ and regulatory IL-10+ Foxp3+ RORgamma t+ T cells. J. Exp. Med. 205, 1381-1393.

Macian, F. (2005). NFAT proteins: key regulators of T-cell development 
and function. Nat. Rev. Immunol. 5, 472-484.

Macian, F., Garcia-Cozar, F., Im, S. H., Horton, H. F., Byrne, M. C., and Rao, A. (2002). Transcriptional mechanisms underlying lymphocyte tolerance. Cell 109, 719-731.

Macian, F., Lopez-Rodriguez, C., and Rao, A. (2001). Partners in transcription: NFAT and AP-1. Oncogene 20, 2476-2489.

Mamura, M., Lee, W., Sullivan, T. J., Felici, A., Sowers, A. L., Allison, J. P., and Letterio, J. J. (2004). CD28 disruption exacerbates inflammation in Tgf-beta1-/- mice: in vivo suppression by $\mathrm{CD} 4+\mathrm{CD} 25+$ regulatory $\mathrm{T}$ cells independent of autocrine TGFbetal. Blood 103, 4594-4601.

Mandapathil, M., Hilldorfer, B., Szczepanski, M. J., Czystowska, M., Szajnik, M., Ren, J., Lang, S., Jackson, E. K., Gorelik, E., and Whiteside, T. L. (2010). Generation and accumulation of immunosuppressive adenosine by human CD4+CD25highFOXP3+ regulatory T cells. J. Biol. Chem. 285, 7176-7186.

Mandapathil, M., Lang, S., Gorelik, E., and Whiteside, T. L. (2009). Isolation of functional human regulatory $\mathrm{T}$ cells (Treg) from the peripheral blood based on the CD39 expression. J. Immunol. Methods 346, 55-63.

Manicassamy, S., Gupta, S., and Sun, Z. (2006a). Selective function of PKCtheta in T cells. Cell. Mol. Immunol. 3, 263-270.

Manicassamy, S., Sadim, M., Ye, R. D., and Sun, Z. (2006b). Differential roles of PKC-theta in the regulation of intracellular calcium concentration in primary T cells. J. Mol. Biol. $355,347-359$

Marie, J. C., Letterio, J. J., Gavin, M., and Rudensky, A. Y. (2005). TGF-betal maintains suppressor function and Foxp3 expression in $\mathrm{CD} 4+\mathrm{CD} 25+$ regulatory T cells. J. Exp. Med. 201, 1061-1067.

Marie, J. C., Liggitt, D., and Rudensky, A. Y. (2006). Cellular mechanisms of fatal early-onset autoimmunity in mice with the $\mathrm{T}$ cellspecific targeting of transforming growth factor-beta receptor. Immunity 25, 441-454.

Mauri, C., and Ehrenstein, M. R. (2008). The "short" history of regulatory B cells. Trends Immunol. 29, 34-40.

McGeachy, M. J., and Anderton, S. M. (2005). Cytokines in the induction and resolution of experimental autoimmune encephalomyelitis. Cytokine 32, 81-84.
Mempel, T. R., Pittet, M. J., Khazaie, K., Weninger, W., Weissleder, R., von Boehmer, H., and von Andrian, U. H. (2006). Regulatory T cells reversibly suppress cytotoxic $\mathrm{T}$ cell function independent of effector differentiation. Immunity 25, 129-141.

Mittelstadt, P. R., Yamaguchi, H., Appella, E., and Ashwell, J. D. (2009). T cell receptor-mediated activation of $\mathrm{p} 38$ \{alpha\} by monophosphorylation of the activation loop results in altered substrate specificity. J. Biol. Chem. 284, 15469-15474.

Miyara, M., Yoshioka, Y., Kitoh, A., Shima, T., Wing, K., Niwa, A., Parizot, C., Taflin, C., Heike, T., Valeyre, D., Mathian, A., Nakahata, T., Yamaguchi, T., Nomura, T., Ono, M., Amoura, Z., Gorochov, G., and Sakaguchi, S. (2009). Functional delineation and differentiation dynamics of human $\mathrm{CD} 4+\mathrm{T}$ cells expressing the FoxP3 transcription factor. Immunity 30, 899-911.

Moore, K. W., de Waal, M. R., Coffman, R. L., and O'Garra, A. (2001). Interleukin-10 and the interleukin10 receptor. Annu. Rev. Immunol. 19, 683-765.

Murai, M., Turovskaya, O., Kim, G., Madan, R., Karp, C. L., Cheroutre, H., and Kronenberg, M. (2009). Interleukin 10 acts on regulatory $\mathrm{T}$ cells to maintain expression of the transcription factor Foxp3 and suppressive function in mice with colitis. Nat. Immunol. 10, 1178-1184.

Nagaleekar, V. K., Diehl, S. A., Juncadella, I., Charland, C., Muthusamy, N., Eaton, S., Haynes, L., GarrettSinha, L. A., Anguita, J., and Rincon, M. (2008). IP3 receptor-mediated $\mathrm{Ca} 2+$ release in naive $\mathrm{CD} 4 \mathrm{~T}$ cells dictates their cytokine program. $J$. Immunol. 181, 8315-8322.

Nakamura, K., Kitani, A., Fuss, I., Pedersen, A., Harada, N., Nawata, H., and Strober, W. (2004). TGF-beta 1 plays an important role in the mechanism of $\mathrm{CD} 4+\mathrm{CD} 25+$ regulatory $\mathrm{T}$ cell activity in both humans and mice. J. Immunol. 172, 834-842.

Nakamura, K., Kitani, A., and Strober, W. (2001). Cell contactdependent immunosuppression by $\mathrm{CD} 4(+) \mathrm{CD} 25(+)$ regulatory $\mathrm{T}$ cells is mediated by cell surface-bound transforming growth factor beta. $J$. Exp. Med. 194, 629-644.

Oberle, N., Eberhardt, N., Falk, C. S., Krammer, P. H., and SuriPayer, E. (2007). Rapid suppression of cytokine transcription in human $\mathrm{CD} 4+\mathrm{CD} 25 \mathrm{~T}$ Cells by CD4+Foxp3+ regulatory $\mathrm{T}$ cells: independence of IL-2 consumption,
TGF-beta, and various inhibitors of TCR signaling. J. Immunol. 179, 3578-3587.

Oderup, C., Cederbom, L., Makowska, A., Cilio, C. M., and Ivars, F. (2006). Cytotoxic $\mathrm{T}$ lymphocyte antigen4-dependent down-modulation of costimulatory molecules on dendritic cells in CD4+ CD25+ regulatory T-cell-mediated suppression. Immunology 118, 240-249.

Ohashi, P. S., and Yeh, W. C. (2006). Supressing the supressors. Nat. Med. $12,1000-1002$.

Oh-Hora, M., and Rao, A. (2008). Calcium signaling in lymphocytes. Curr. Opin. Immunol. 20, 250-258.

Oh-Hora, M., Yamashita, M., Hogan, P. G., Sharma, S., Lamperti, E., Chung, W., Prakriya, M., Feske, S., and Rao, A. (2008). Dual functions for the endoplasmic reticulum calcium sensors STIM1 and STIM2 in T cell activation and tolerance. Nat. Immunol. 9, 432-443.

Omilusik, K., Priatel, J. J., Chen, X., Wang, Y. T., Xu, H., Choi, K. B., Gopaul, R., McIntyre-Smith, A., Teh, H. S., Tan, R., Bech-Hansen, N. T. Waterfield, D., Fedida, D., Hunt, S. V., and Jefferies, W. A. (2011). The $\mathrm{Ca}(\mathrm{v}) 1.4$ calcium channel is a critical regulator of $\mathrm{T}$ cell receptor signaling and naive $\mathrm{T}$ cell homeostasis. Immunity 35, 349-360.

Onishi, Y., Fehervari, Z., Yamaguchi, T., and Sakaguchi, S. (2008). Foxp3+ natural regulatory $\mathrm{T}$ cells preferentially form aggregates on dendritic cells in vitro and actively inhibit their maturation. Proc. Natl. Acad. Sci. U.S.A. 105, 10113-10118.

Oruganti, S. R., Edin, S., Grundstrom, C., and Grundstrom, T. (2011). CaMKII targets Bcllo in T-cell receptor induced activation of NF-kappaB. Mol. Immunol. 48, 1448-1460.

Osorio, F., LeibundGut-Landmann, S. Lochner, M., Lahl, K., Sparwasser, T. Eberl, G., and Reis e Sousa, C. (2008). DC activated via dectin-1 convert Treg into IL-17 producers. Eur. J. Immunol. 38, 3274-3281.

Palkowitsch, L., Marienfeld, U., Brunner, C., Eitelhuber, A., Krappmann, D., and Marienfeld, R. B. (2011). The Ca2+-dependent phosphatase calcineurin controls the formation of the Carma1/Bcl10/Malt1 complex during $\mathrm{T}$ cell receptor induced NF\{kappa\}B activation. J. Biol. Chem. 286, 7522-7534.

Pandiyan, P., Conti, H. R., Zheng, L., Peterson, A. C., Mathern, D. R., Hernandez-Santos, N., Edgerton, M., Gaffen, S. L., and Lenardo, M. J. (2011). CD4(+)CD25(+)Foxp3(+) regulatory $\mathrm{T}$ cells promote $\mathrm{Th} 17$ cells in vitro and enhance host resistance in mouse Candida albicans Th17 cell infection model. Immunity 34 422-434.

Pandiyan, P., Zheng, L., Ishihara, S., Reed, J., and Lenardo, M. J. (2007) $\mathrm{CD} 4+\mathrm{CD} 25+$ Foxp3+ regulatory $\mathrm{T}$ cells induce cytokine deprivationmediated apoptosis of effector CD4+ T cells. Nat. Immunol. 8, 1353-1362.

Park, C. Y., Shcheglovitov, A., and Dolmetsch, R. (2010). The CRAC channel activator STIM1 binds and inhibits L-type voltage-gated calcium channels. Science 330 , 101-105.

Peggs, K. S., Quezada, S. A., Chambers, C. A., Korman, A. J., and Allison, J. P. (2009). Blockade of CTLA-4 on both effector and regulatory $\mathrm{T}$ cell compartments contributes to the antitumor activity of anti-CTLA-4 antibodies. J. Exp. Med. 206, 1717-1725.

Peiser, M., Becht, A., and Wanner, R. (2007). Antibody blocking of MHC II on human activated regulatory $\mathrm{T}$ cells abrogates their suppressive potential. Allergy 62, 773-780.

Perkins, N. D. (2006). Post-translational modifications regulating the activity and function of the nuclear factor kappa B pathway. Oncogene 25, 6717-6730.

Pfeifhofer, C., Kofler, K., Gruber, T., Tabrizi, N. G., Lutz, C., Maly, K., Leitges, M., and Baier, G. (2003). Protein kinase $\mathrm{C}$ theta affects $\mathrm{Ca} 2+$ mobilization and NFAT cell activation in primary mouse T cells. J. Exp. Med. 197, 1525-1535.

Piccirillo, C. A., Letterio, J. J., Thornton, A. M., McHugh, R. S., Mamura, M., Mizuhara, H., and Shevach, E. M. (2002). CD4(+)CD25(+) regulatory $\mathrm{T}$ cells can mediate suppressor function in the absence of transforming growth factor betal production and responsiveness. J. Exp. Med. 196, 237-246.

Pierau, M., Engelmann, S., Reinhold, D., Lapp, T., Schraven, B., and Bommhardt, U. H. (2009). Protein kinase B/Akt signals impair Th17 differentiation and support natural regulatory $\mathrm{T}$ cell function and induced regulatory $\mathrm{T}$ cell formation. J. Immunol. 183, 6124-6134.

Pillai, V., and Karandikar, N. J. (2008). Attack on the clones? Human FOXP3 detection by PCH101, 236A/E7, 206D, and 259D reveals 259D as the outlier with lower sensitivity. Blood 111, 463-464.

Pillai, V., Ortega, S. B., Wang, C. K., and Karandikar, N. J. (2007). Transient regulatory T-cells: a state attained 
by all activated human T-cells. Clin. Immunol. 123, 18-29.

Podtschaske, M., Benary, U., Zwinger, S., Hofer, T., Radbruch, A., and Baumgrass, R. (2007). Digital NFATc2 activation per cell transforms graded $\mathrm{T}$ cell receptor activation into an all-or-none IL-2 expression. PLoS ONE 2, e935. doi:10.1371/journal.pone. 0000935

Qi, Q., and August, A. (2007). Keeping the (kinase) party going: SLP-76 and ITK dance to the beat. Sci. STKE 2007, e39.

Quintana, A., Griesemer, D., Schwarz, E. C., and Hoth, M. (2005). Calcium-dependent activation of Tlymphocytes. Pflugers Arch. 450, 1-12.

Qureshi, O. S., Zheng, Y., Nakamura, K., Attridge, K., Manzotti, C., Schmidt, E. M., Baker, J., Jeffery, L. E., Kaur, S., Briggs, Z., Hou, T. Z., Futter, C. E., Anderson, G., Walker, L. S., and Sansom, D. M. (2011). Transendocytosis of CD80 and CD86: a molecular basis for the cell-extrinsic function of CTLA-4. Science 332, 600-603.

Ranger, A. M., Oukka, M., Rengarajan, J., and Glimcher, L. H. (1998). Inhibitory function of two NFAT family members in lymphoid homeostasis and Th2 development. Immunity 9, 627-635.

Rao, A., Luo, C., and Hogan, P. G. (1997). Transcription factors of the NFAT family: regulation and function. Annu. Rev. Immunol. 15, 707-747.

Read, S., Greenwald, R., Izcue, A., Robinson, N., Mandelbrot, D., Francisco, L., Sharpe, A. H., and Powrie, F. (2006). Blockade of CTLA-4 on $\mathrm{CD} 4+\mathrm{CD} 25+$ regulatory $\mathrm{T}$ cells abrogates their function in vivo. $J$. Immunol. 177, 4376-4383.

Read, S., Malmstrom, V., and Powrie, F. (2000). Cytotoxic T lymphocyteassociated antigen 4 plays an essential role in the function of $\mathrm{CD} 25(+) \mathrm{CD} 4(+)$ regulatory cells that control intestinal inflammation. J. Exp. Med. 192, 295-302.

Ren, X., Ye, F., Jiang, Z., Chu, Y., Xiong, S., and Wang, Y. (2007). Involvement of cellular death in TRAIL/DR5-dependent suppression induced by $\mathrm{CD} 4(+) \mathrm{CD} 25(+)$ regulatory T cells. Cell Death Differ. 14, 2076-2084.

Roncador, G., Brown, P. J., Maestre, L., Hue, S., Martinez-Torrecuadrada, J. L., Ling, K. L., Pratap, S., Toms, C., Fox, B. C., Cerundolo, V., Powrie, F., and Banham, A. H. (2005). Analysis of FOXP3 protein expression in human $\mathrm{CD} 4+\mathrm{CD} 25+$ regulatory $\mathrm{T}$ cells at the single-cell level. Eur. J. Immunol. 35, 1681-1691.

Roncarolo, M. G., Gregori, S., Battaglia, M., Bacchetta, R., Fleischhauer, K., and Levings, M. K. (2006). Interleukin-10-secreting type 1 regulatory $\mathrm{T}$ cells in rodents and humans. Immunol. Rev. 212, 28-50.

Rubtsov, Y. P., Niec, R. E., Josefowicz, S., Li, L., Darce, J., Mathis, D., Benoist, C., and Rudensky, A. Y. (2010). Stability of the regulatory $\mathrm{T}$ cell lineage in vivo. Science 329, 1667-1671.

Rubtsov, Y. P., Rasmussen, J. P., Chi, E. Y., Fontenot, J., Castelli, L., Ye, X., Treuting, P., Siewe, L., Roers, A., Henderson, W. R. Jr., Muller, W., and Rudensky, A. Y. (2008). Regulatory T cellderived interleukin-10 limits inflammation at environmental interfaces. Immunity 28, 546-558.

Sabapathy, K., Kallunki, T., David, J. P., Graef, I., Karin, M., and Wagner, E. F. (2001). c-Jun NH2-terminal kinase (JNK) 1 and JNK2 have similar and stage-dependent roles in regulating $\mathrm{T}$ cell apoptosis and proliferation. $J$. Exp. Med. 193, 317-328.

Sakaguchi, S. (2004). Naturally arising $\mathrm{CD} 4+$ regulatory $\mathrm{t}$ cells for immunologic self-tolerance and negative control of immune responses. Annu. Rev. Immunol. 22, 531-562.

Sakaguchi, S., Sakaguchi, N., Asano, M., Itoh, M., and Toda, M. (1995). Immunologic self-tolerance maintained by activated $\mathrm{T}$ cells expressing IL-2 receptor alpha-chains (CD25). Breakdown of a single mechanism of self-tolerance causes various autoimmune diseases. J. Immunol. $155,1151-1164$.

Sakurai, H., Chiba, H., Miyoshi, H., Sugita, T., and Toriumi, W. (1999). IkappaB kinases phosphorylate NFkappaB p65 subunit on serine 536 in the transactivation domain. J. Biol. Chem. 274, 30353-30356.

Sarris, M., Andersen, K. G., Randow, F., Mayr, L., and Betz, A. G. (2008). Neuropilin-1 expression on regulatory $\mathrm{T}$ cells enhances their interactions with dendritic cells during antigen recognition. Immunity 28 , 402-413.

Schmidt, A., Oberle, N., Weiß, E.-M., Vobis, D., Frischbutter, S., Baumgrass, R., Falk, C. S., Haag, M., Brügger, B., Lin, H., Mayr, G. W., Reichardt, P., Gunzer, M., Suri-Payer, E., and Krammer, P. H. (2011). Human regulatory $\mathrm{T}$ cells rapidly suppress $\mathrm{T}$ cell receptor-induced $\mathrm{Ca}^{+}, \mathrm{NF}-\mathrm{kB}$, and NFAT signaling in conventional T cells. Sci. Signal. 4 , ra90.
Schneider, H., Downey, J., Smith, A., Zinselmeyer, B. H., Rush, C., Brewer, J. M., Wei, B., Hogg, N., Garside, P., and Rudd, C. E. (2006). Reversal of the TCR stop signal by CTLA-4. Science 313, 1972-1975.

Schwarzmann, N., Kunerth, S., Weber, K., Mayr, G. W., and Guse, A. H. (2002). Knock-down of the type 3 ryanodine receptor impairs sustained $\mathrm{Ca} 2+$ signaling via the $\mathrm{T}$ cell receptor/CD3 complex. J. Biol. Chem. 277, 50636-50642.

Serfling, E., Chuvpilo, S., Liu, J., Hofer, T., and Palmetshofer, A. (2006). NFATcl autoregulation: a crucial step for cell-fate determination. Trends Immunol. 27, 461-469.

Sica, A., Dorman, L., Viggiano, V., Cippitelli, M., Ghosh, P., Rice, N., and Young, H. A. (1997). Interaction of NF-kappaB and NFAT with the interferon-gamma promoter. J. Biol. Chem. 272, 30412-30420.

Smith-Garvin, J. E., Koretzky, G. A., and Jordan, M. S. (2009). T cell activation. Annu. Rev. Immunol. 27, 591-619.

Sojka, D. K., and Fowell, D. J. (2011). Regulatory T cells inhibit acute IFNgamma synthesis without blocking T-helper cell type 1 (Th1) differentiation via a compartmentalized requirement for IL-10. Proc. Natl. Acad. Sci. U.S.A. 108, 18336-18341.

Sojka, D. K., Hughson, A., Sukiennicki, T. L., and Fowell, D. J. (2005) Early kinetic window of target $\mathrm{T}$ cell susceptibility to CD25+ regulatory $\mathrm{T}$ cell activity. J. Immunol. 175, 7274-7280.

Song, X. T., Evel-Kabler, K., Shen, L. Rollins, L., Huang, X. F., and Chen, S. Y. (2008). A20 is an antigen presentation attenuator, and its inhibition overcomes regulatory $\mathrm{T}$ cellmediated suppression. Nat. Med. 14, 258-265.

Soto-Nieves, N., Puga, I., Abe, B. T., Bandyopadhyay, S., Baine, I., Rao, A., and Macian, F. (2009). Transcriptional complexes formed by NFAT dimers regulate the induction of T cell tolerance. J. Exp. Med. 206, 867-876.

Spencer, S. D., Di Marco, F., Hooley, J., Pitts-Meek, S., Bauer, M., Ryan, A. M., Sordat, B., Gibbs, V. C., and Aguet, M. (1998). The orphan receptor CRF2-4 is an essential subunit of the interleukin 10 receptor. J. Exp. Med. 187, 571-578.

Stephens, L. A., Mottet, C., Mason, D., and Powrie, F. (2001). Human $\mathrm{CD} 4(+) \mathrm{CD} 25(+)$ thymocytes and peripheral $\mathrm{T}$ cells have immune suppressive activity in vitro. Eur. $J$. Immunol. 31, 1247-1254.
Stummvoll, G. H., DiPaolo, R. J., Huter, E. N., Davidson, T. S., Glass, D., Ward, J. M., and Shevach, E. M. (2008). Th1, Th2, and Th17 effector $\mathrm{T}$ cell-induced autoimmune gastritis differs in pathological pattern and in susceptibility to suppression by regulatory T cells. J. Immunol. 181, 1908-1916.

Sukiennicki, T. L., and Fowell, D. J. (2006). Distinct molecular program imposed on $\mathrm{CD} 4+\mathrm{T}$ cell targets by CD4+CD25+ regulatory T cells. $J$. Immunol. 177, 6952-6961.

Sumoza-Toledo, A., Eaton, A. D., and Sarukhan, A. (2006). Regulatory T cells inhibit protein kinase $\mathrm{C}$ theta recruitment to the immune synapse of naive $\mathrm{T}$ cells with the same antigen specificity. J. Immunol. 176, 5779-5787.

Sun, Z., Arendt, C. W., Ellmeier, W. Schaeffer, E. M., Sunshine, M. J., Gandhi, L., Annes, J., Petrzilka, D., Kupfer, A., Schwartzberg, P. L., and Littman, D. R. (2000). PKC-theta is required for TCR-induced NFkappaB activation in mature but not immature $\mathrm{T}$ lymphocytes. Nature 404, 402-407.

Suri-Payer, E., and Fritzsching, B. (2006). Regulatory $\mathrm{T}$ cells in experimental autoimmune disease. Springer Semin. Immunopathol. 28, 3-16.

Suvas, S., Kumaraguru, U., Pack, C. D., Lee, S., and Rouse, B. T. (2003). $\mathrm{CD} 4+\mathrm{CD} 25+\mathrm{T}$ cells regulate virusspecific primary and memory CD $8+$ T cell responses. J. Exp. Med. 198, 889-901.

Szymczak-Workman, A. L., Delgoffe, G. M., Green, D. R., and Vignali, D. A (2011). Cutting edge: regulatory $\mathrm{T}$ cells do not mediate suppression via programmed cell death pathways. $J$. Immunol. 187, 4416-4420.

Szymczak-Workman, A. L., Workman, C. J., and Vignali, D. A. (2009). Cutting edge: regulatory $\mathrm{T}$ cells do not require stimulation through their TCR to suppress. J. Immunol. 182, 5188-5192.

Taams, L. S., Smith, J., Rustin, M. H., Salmon, M., Poulter, L. W., and Akbar, A. N. (2001). Human anergic/suppressive $\mathrm{CD} 4(+) \mathrm{CD} 25(+) \mathrm{T}$ cells: a highly differentiated and apoptosis-prone population. Eur. J. Immunol. 31, 1122-1131.

Tadokoro, C. E., Shakhar, G., Shen, S., Ding, Y., Lino, A. C., Maraver, A., Lafaille, J. J., and Dustin, M. L. (2006). Regulatory T cells inhibit stable contacts between $\mathrm{CD} 4+\mathrm{T}$ cells and dendritic cells in vivo. J. Exp. Med. 203, 505-511. 
Takahashi, T., Kuniyasu, Y., Toda, M., Sakaguchi, N., Itoh, M., Iwata, M., Shimizu, J., and Sakaguchi, S. (1998). Immunologic self-tolerance maintained by $\mathrm{CD} 25+\mathrm{CD} 4+$ naturally anergic and suppressive $\mathrm{T}$ cells: induction of autoimmune disease by breaking their anergic/suppressive state. Int. Immunol. 10, 1969-1980.

Takahashi, T., Tagami, T., Yamazaki, S., Uede, T., Shimizu, J., Sakaguchi, N., Mak, T. W., and Sakaguchi, S. (2000). Immunologic self-tolerance maintained by CD25(+)CD4(+) regulatory $\mathrm{T}$ cells constitutively expressing cytotoxic $\mathrm{T}$ lymphocyte-associated antigen 4. J. Exp. Med. 192, 303-310.

Tanchot, C., Vasseur, F., Pontoux, C., Garcia, C., and Sarukhan, A. (2004). Immune regulation by self-reactive $\mathrm{T}$ cells is antigen specific. J. Immunol. 172, 4285-4291.

Tang, Q., and Bluestone, J. A. (2008). The Foxp3+ regulatory T cell: a jack of all trades, master of regulation. Nat. Immunol. 9, 239-244.

Tang, Q., Boden, E. K., Henriksen, K. J., Bour-Jordan, H., Bi, M., and Bluestone, J. A. (2004). Distinct roles of CTLA-4 and TGFbeta in $\mathrm{CD} 4+\mathrm{CD} 25+$ regulatory $\mathrm{T}$ cell function. Eur. J. Immunol. 34, 2996-3005.

Tang, Q., and Krummel, M. F. (2006). Imaging the function of regulatory T cells in vivo. Curr. Opin. Immunol. 18, 496-502.

Thornton, A. M., Donovan, E. E., Piccirillo, C. A., and Shevach, E. M. (2004a). Cutting edge: IL-2 is critically required for the in vitro activation of $\mathrm{CD} 4+\mathrm{CD} 25+\mathrm{T}$ cell suppressor function. J. Immunol. 172, 6519-6523.

Thornton, A. M., Piccirillo, C. A., and Shevach, E. M. (2004b). Activation requirements for the induction of CD4+CD25+ $\mathrm{T}$ cell suppressor function. Eur. J. Immunol. 34, 366-376.

Thornton, A. M., and Shevach, E. M. (1998). CD4+CD25+ immunoregulatory $\mathrm{T}$ cells suppress polyclonal $\mathrm{T}$ cell activation in vitro by inhibiting interleukin 2 production. J. Exp. Med. 188, 287-296.

Thornton, A. M., and Shevach, E. M. (2000). Suppressor effector function of CD4+CD25+ immunoregulatory $\mathrm{T}$ cells is antigen nonspecific. J. Immunol. 164, 183-190.

Tran, D. Q., Glass, D. D., Uzel, G., Darnell, D. A., Spalding, C., Holland, S. M., and Shevach, E. M. (2009). Analysis of adhesion molecules, target cells, and role of IL2 in human FOXP3+ regulatory $\mathrm{T}$ cell suppressor function. J. Immunol. 182, 2929-2938.

Tran, D. Q., Ramsey, H., and Shevach, E. M. (2007). Induction of FOXP3 expression in naive human CD4+FOXP3 $\mathrm{T}$ cells by $\mathrm{T}$-cell receptor stimulation is transforming growth factor-beta dependent but does not confer a regulatory phenotype. Blood 110, 2983-2990.

Travis, M. A., Reizis, B., Melton, A. C., Masteller, E., Tang, Q., Proctor, J. M., Wang, Y., Bernstein, X., Huang, X., Reichardt, L. F., Bluestone, J. A., and Sheppard, D. (2007). Loss of integrin alpha(v)beta8 on dendritic cells causes autoimmunity and colitis in mice. Nature 449, 361-365.

Trushin, S. A., Pennington, K. N., Algeciras-Schimnich, A., and Paya, C. V. (1999). Protein kinase C and calcineurin synergize to activate IkappaB kinase and NF-kappaB in T lymphocytes. J. Biol. Chem. 274, 22923-22931.

Uhlig, H. H., Coombes, J., Mottet, C., Izcue, A., Thompson, C., Fanger, A., Tannapfel, A., Fontenot, J. D., Ramsdell, F., and Powrie, F. (2006). Characterization of Foxp3+CD4+CD25+ and IL-10secreting $\mathrm{CD} 4+\mathrm{CD} 25+\mathrm{T}$ cells during cure of colitis. J. Immunol. 177, 5852-5860.

Vaeth, M., Gogishvili, T., Bopp, T., Klein, M., Berberich-Siebelt, F., Gattenloehner, S., Avots, A., Sparwasser, T., Grebe, N., Schmitt, E., Hunig, T., Serfling, E., and Bodor, J. (2011). Regulatory $\mathrm{T}$ cells facilitate the nuclear accumulation of inducible cAMP early repressor (ICER) and suppress nuclear factor of activated $\mathrm{T}$ cell cl (NFATc1). Proc. Natl. Acad. Sci. U.S.A. 108, 2480-2485.

Vallabhapurapu, S., and Karin, M. (2009). Regulation and function of NF-kappaB transcription factors in the immune system. Annu. Rev. Immunol. 27, 693-733.

van der Merwe, P. A., Bodian, D. L., Daenke, S., Linsley, P., and Davis, S. J. (1997). CD80 (B7-1) binds both CD28 and CTLA-4 with a low affinity and very fast kinetics. J. Exp. Med. 185, 393-403.

Veldhoen, M., Moncrieffe, H., Hocking, R. J., Atkins, C. J., and Stockinger, B. (2006). Modulation of dendritic cell function by naive and regulatory CD4+ T cells. J. Immunol. 176, 6202-6210.

Vercoulen, Y., Wehrens, E. J., van Teijlingen, N. H., de Jager, W., Beekman, J. M., and Prakken, B. J. (2009). Human regulatory $\mathrm{T}$ cell suppressive function is independent of apoptosis induction in activated effector T cells. PLoS ONE 4, e7183. doi:10.1371/journal.pone.0007183

Villarino, A. V., Tato, C. M., Stumhofer, J. S., Yao, Z., Cui, Y. K., Hennighausen, L., O'Shea, J. J., and Hunter, C. A. (2007). Helper T cell IL-2 production is limited by negative feedback and STAT-dependent cytokine signals. J. Exp. Med. 204, 65-71.

Voo, K. S., Wang, Y. H., Santori, F. R., Boggiano, C., Wang, Y. H., Arima, K., Bover, L., Hanabuchi, S., Khalili, J., Marinova, E., Zheng, B., Littman, D. R., and Liu, Y. J. (2009). Identification of IL-17producing FOXP3+ regulatory $\mathrm{T}$ cells in humans. Proc. Natl. Acad. Sci. U.S.A. 106, 4793-4798.

Walker, M. R., Kasprowicz, D. J., Gersuk, V. H., Benard, A., Van, L. M., Buckner, J. H., and Ziegler, S. F. (2003). Induction of FoxP3 and acquisition of T regulatory activity by stimulated human CD4+. J. Clin. Invest. 112, 1437-1443.

Walunas, T. L., Bakker, C. Y., and Bluestone, J. A. (1996). CTLA-4 ligation blocks CD28-dependent T cell activation. J. Exp. Med. 183, 2541-2550.

Walunas, T. L., Lenschow, D. J., Bakker, C. Y., Linsley, P. S., Freeman, G. J., Green, J. M., Thompson, C. B., and Bluestone, J. A. (1994). CTLA-4 can function as a negative regulator of $\mathrm{T}$ cell activation. Immunity 1 , 405-413.

Wang, J., Ioan-Facsinay, A., van, D. V., Huizinga, T. W., and Toes, R. E. (2007). Transient expression of FOXP3 in human activated nonregulatory $\mathrm{CD} 4+\mathrm{T}$ cells. Eur. J. Immunol. 37, 129-138.

Wang, Y., Deng, X., Mancarella, S. Hendron, E., Eguchi, S., Soboloff, J., Tang, X. D., and Gill, D. L. (2010). The calcium store sensor, STIM1, reciprocally controls Orai and CaV1.2 channels. Science 330, 105-109.

Wang, Y., Su, M. A., and Wan, Y. Y. (2011). An essential role of the transcription factor GATA-3 for the function of regulatory T cells. Immunity 35, 337-348.

Wehrens, E. J., Mijnheer, G., Duurland, C. L., Klein, M., Meerding, J., van Loosdregt, J., de Jager, W., Sawitzki, B., Coffer, P. J., Vastert, B., Prakken, B. J., and van Wijk, F. (2011). Functional human regulatory $\mathrm{T}$ cells fail to control autoimmune inflammation due to $\mathrm{PKB} / \mathrm{c}$-akt hyperactivation in effector cells. Blood 118 , 3538-3548.

Werlen, G., Jacinto, E., Xia, Y., and Karin, M. (1998). Calcineurin preferentially synergizes with PKC-theta to activate JNK and IL-2 promoter in T lymphocytes. EMBO J. 17, 3101-3111.

Wing, K., Onishi, Y., Prieto-Martin, P., Yamaguchi, T., Miyara, M., Fehervari, Z., Nomura, T., and Sakaguchi, S. (2008). CTLA-4 control over Foxp3+ regulatory T cell function. Science 322, 271-275.

Wohlfert, E. A., Callahan, M. K., and Clark, R. B. (2004). Resistance to CD4+CD25+ regulatory $\mathrm{T}$ cells and TGF-beta in Cbl-b-/- mice. J. Immunol. 173, 1059-1065.

Wohlfert, E. A., and Clark, R. B. (2007). "Vive la Resistance!" - the PI3KAkt pathway can determine target sensitivity to regulatory $\mathrm{T}$ cell suppression. Trends Immunol. 28, 154-160.

Wohlfert, E. A., Grainger, J. R. Bouladoux, N., Konkel, J. E., Oldenhove, G., Ribeiro, C. H., Hall, J. A., Yagi, R., Naik, S., Bhairavabhotla, R., Paul, W. E., Bosselut, R., Wei, G., Zhao, K., Oukka, M., Zhu, J., and Belkaid, Y. (2011). GATA3 controls Foxp3+ regulatory $\mathrm{T}$ cell fate during inflammation in mice. J. Clin. Invest. 121, 4503-4515.

Workman, C. J., and Vignali, D. A. (2005). Negative regulation of T cell homeostasis by lymphocyte activation gene-3 (CD223). J. Immunol. 174, 688-695.

Xu, L., Kitani, A., Fuss, I., and Strober, W. (2007). Cutting edge: regulatory $\mathrm{T}$ cells induce CD4+CD25-Foxp3$\mathrm{T}$ cells or are self-induced to become Th17 cells in the absence of exogenous TGF-beta. J. Immunol. 178 , 6725-6729.

Yagi, H., Nomura, T., Nakamura, K., Yamazaki, S., Kitawaki, T., Hori, S., Maeda, M., Onodera, M., Uchiyama, T., Fujii, S., and Sakaguchi, S. (2004) Crucial role of FOXP3 in the development and function of human CD25+CD4+ regulatory T cells. Int . Immunol. 16, 1643-1656.

Yan, Z., Garg, S. K., and Banerjee, R. (2010). Regulatory T cells interfere with glutathione metabolism in dendritic cells and T cells. J. Biol. Chem. 285, 41525-41532.

Yan, Z., Garg, S. K., Kipnis, J., and Banerjee, R. (2009). Extracellular redox modulation by regulatory $\mathrm{T}$ cells. Nat. Chem. Biol. 5, 721-723.

Yang, X. O., Nurieva, R., Martinez, G. J., Kang, H. S., Chung, Y., Pappu, B. P., Shah, B., Chang, S. H., Schluns, K. S., Watowich, S. S., Feng, X. H., Jetten, A. M., and Dong, C. (2008). Molecular antagonism and plasticity of regulatory and inflammatory $\mathrm{T}$ cell programs. Immunity 29, 44-56.

Yang, X. O., Panopoulos, A. D., Nurieva, R., Chang, S. H., Wang, 
D., Watowich, S. S., and Dong, C. (2007). STAT3 regulates cytokinemediated generation of inflammatory helper $\mathrm{T}$ cells. J. Biol. Chem. 282, 9358-9363.

Yao, Z., Kanno, Y., Kerenyi, M., Stephens, G., Durant, L., Watford, W. T., Laurence, A., Robinson, G. W., Shevach, E. M., Moriggl, R., Hennighausen, L., Wu, C., and O'Shea, J. J. (2007). Nonredundant roles for Stat $5 \mathrm{a} / \mathrm{b}$ in directly regulating Foxp3. Blood 109, 4368-4375.

Young, H. A. (1996). Regulation of interferon-gamma gene expression. J. Interferon Cytokine Res. 16, 563-568.

Zarek, P. E., Huang, C. T., Lutz, E. R., Kowalski, J., Horton, M. R., Linden, J., Drake, C. G., and Powell, J. D. (2008). A2A receptor signaling promotes peripheral tolerance by inducing T-cell anergy and the generation of adaptive regulatory T cells. Blood 111, 251-259.

Zheng, Y., Chaudhry, A., Kas, A., DeRoos, P., Kim, J. M., Chu, T. T., Corcoran, L., Treuting, P., Klein, U., and Rudensky, A. Y. (2009). Regulatory T-cell suppressor program co-opts transcription factor IRF4 to control $\mathrm{T}(\mathrm{H}) 2$ responses. Nature 458, 351-356.

Zheng, Y., Manzotti, C. N., Burke, F. Dussably, L., Qureshi, O., Walker, L. S., and Sansom, D. M. (2008). Acquisition of suppressive function by activated human CD4+CD25- T cells is associated with the expression of CTLA-4 not FoxP3. J. Immunol. 181, 1683-1691.

Zhou, L., Lopes, J. E., Chong, M. M., Ivanov, I. I., Min, R., Victora, G. D., Shen, Y., Du, J., Rubtsov, Y. P., Rudensky, A. Y., Ziegler, S. F., and Littman, D.
R. (2008). TGF-beta-induced Foxp3 inhibits $\mathrm{T}(\mathrm{H}) 17$ cell differentiation by antagonizing RORgammat function. Nature 453, 236-240.

Zhou, X., Bailey-Bucktrout, S. L., Jeker, L. T., Penaranda, C., MartinezLlordella, M., Ashby, M., Nakayama, M., Rosenthal, W., and Bluestone, J. A. (2009). Instability of the transcription factor Foxp3 leads to the generation of pathogenic memory $\mathrm{T}$ cells in vivo. Nat. Immunol. 10 1000-1007.

Zou, W. (2006). Regulatory T cells, tumour immunity and immunotherapy. Nat. Rev. Immunol. 6, 295-307.

Conflict of Interest Statement: The authors declare that the research was conducted in the absence of any commercial or financial relationships that could be construed as a potential conflict of interest.

Received: 28 December 2011; paper pending published: 27 January 2012; accepted: 01 March 2012; published online: 21 March 2012.

Citation: Schmidt A, Oberle $N$ and Krammer PH (2012) Molecular mechanisms of Treg-mediated $T$ cell suppression. Front. Immun. 3:51. doi: 10.3389/fimmu.2012.00051

This article was submitted to Frontiers in $T$ Cell Biology, a specialty of Frontiers in Immunology.

Copyright (c) 2012 Schmidt, Oberle and Krammer. This is an open-access article distributed under the terms of the Creative Commons Attribution Non Commercial License, which permits noncommercial use, distribution, and reproduction in other forums, provided the original authors and source are credited. 